\title{
NIST
PUBLICATIONS
}

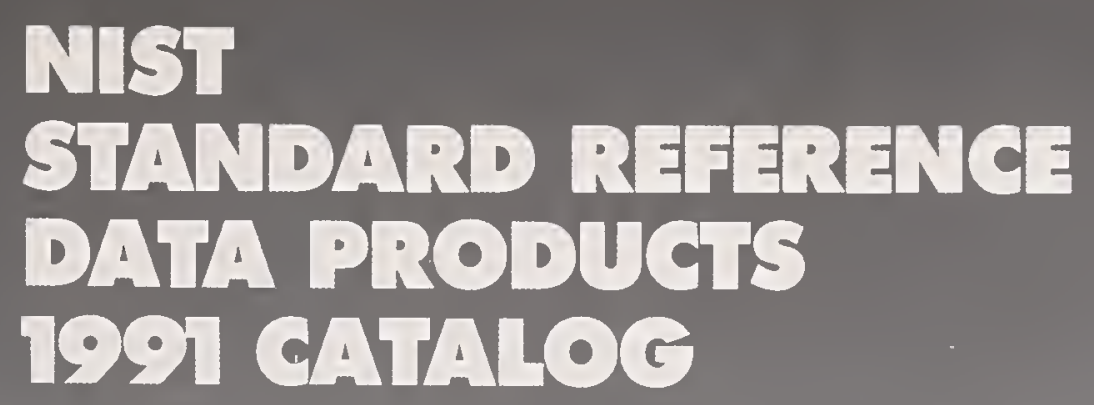

SP782

1991 Edition

$-Q C$

100

.457

\#782

TO ORDER:
(301) $975-2208$

$\omega+\infty+1+\infty \omega_{2}$

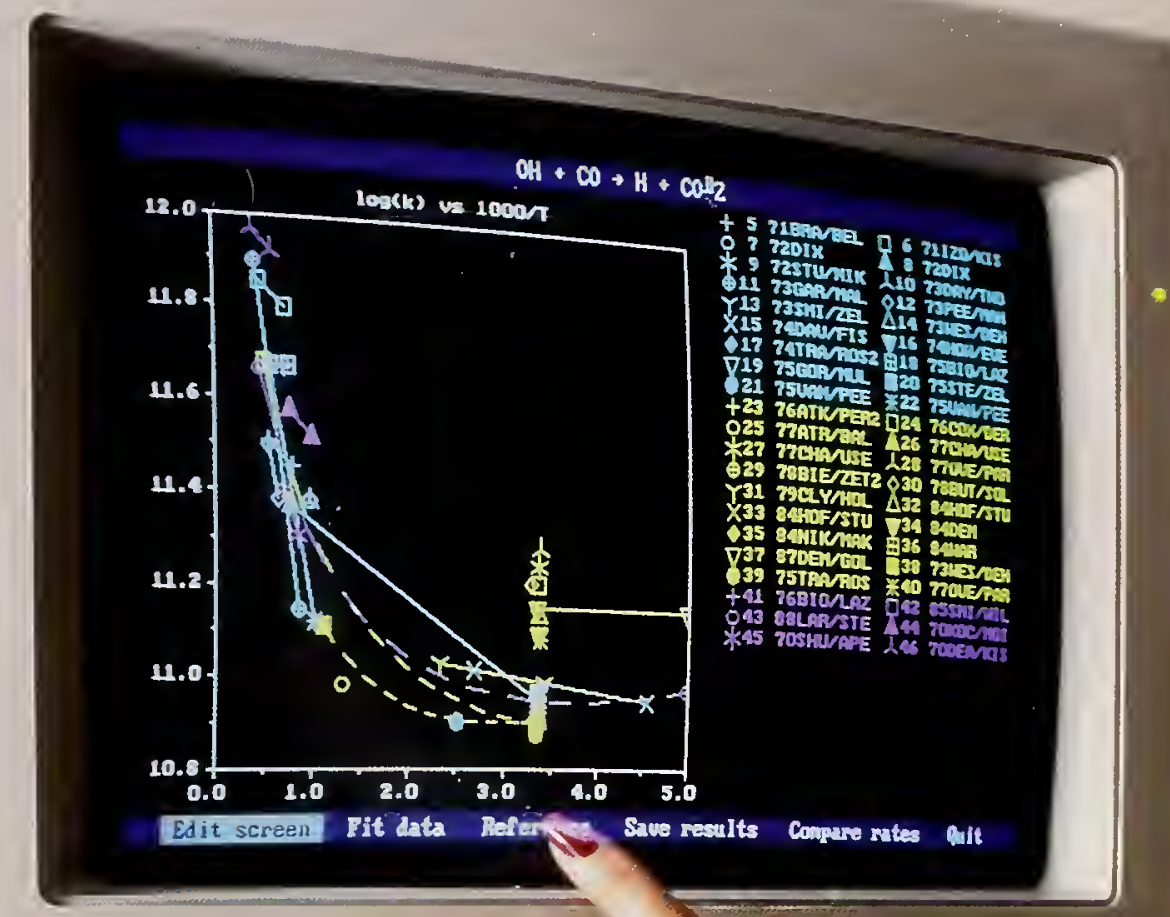

concusts

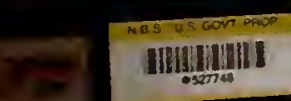

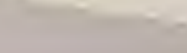

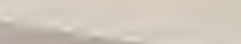





\section{NIST Standard Reference Data Products 1991 Catalog}

Malcolm W. Chase, Jr. and Joan C. Sauerwein, Editors

Standard Reference Data

National Institute of Standards and Technology

Gaithersburg, MD 20899

February 1991

Supersedes NIST Special Publication 782

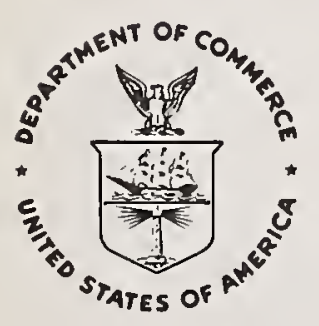

U.S. Department of Commerce

Robert A. Mosbacher, Secretary

National Institute of Standards and Technology

John W. Lyons, Director 
National Institute of Standards and Technology

Special Publication 782,

1991 Edition

Natl. Inst. Stand. Technol.

Spec. Publ. 782, 1991 Ed.

52 pages (Feb. 1991)

CODEN: NSPUE2
U.S. Government Printing Office

Washington: 1991

For sale by the Superintendent of Documents

U.S. Government Printing Office Washington, DC 20402 


\section{ACKNOWLEDGMENTS}

The editors would like to acknowledge Cheryl E. Williams for the electronic typesetting of this document, Jeanne R. Bride for her assistance in proofreading, and H. M. Helfer for his photography. 


\section{ABSTRACT AND KEY WORDS}

The National Institute of Standards and Technology's Standard Reference Data Program provides reliable, welldocumented data to scientists and engineers for use in technical problem-solving, research, and development. This catalog lists classic data compilations in hard-copy form and current databases in the Standard Reference Database Series. This edition of the catalog updates many new databases. These data compilations have been subdivided into seven categories. Prices and ordering information are located at the back of the document.

Key words: atomic physics; chemistry; compilations; databases; materials; numeric data 


\section{PREFACE}

The formal existence of the National Standard Reference Data System dates from 1963, when the Federal Council for Science and Technology asked the then National Bureau of Standards to assume primary responsibility in the Federal Government for promoting and coordinating the critical evaluation of numerical data in the physical sciences. The program was conceived as a decentralized national effort with financial support coming from a variety of government and private sources, but with NBS responsible for the overall planning and coordination. In 1968 Congress provided a specific legislative mandate for the program through passage of Public Law 90-396, the Standard Reference Data Act. This Act states the policy of Congress to make reliable reference data available to scientists, engineers, and the general public.

The Standard Reference Data Program has been providing evaluated, high-quality data for a wide range of applications to industry, government, and academic institutions for over twenty-seven years. Standard reference data has been utilized to improve design efficiency of various chemical processes, identify potentially toxic substances in the environment, improve materials durability, and calculate performance of chemical reactors, to name but a few applications. With the onset of the personal computer at every scientist's fingertips, standard reference data is even more accessible and will play an even more critical role in the future. With this, the second annual Standard Reference Data Products Catalog, we hope to make the scientific community more aware of our highly evaluated, high-quality data in all of its many forms.

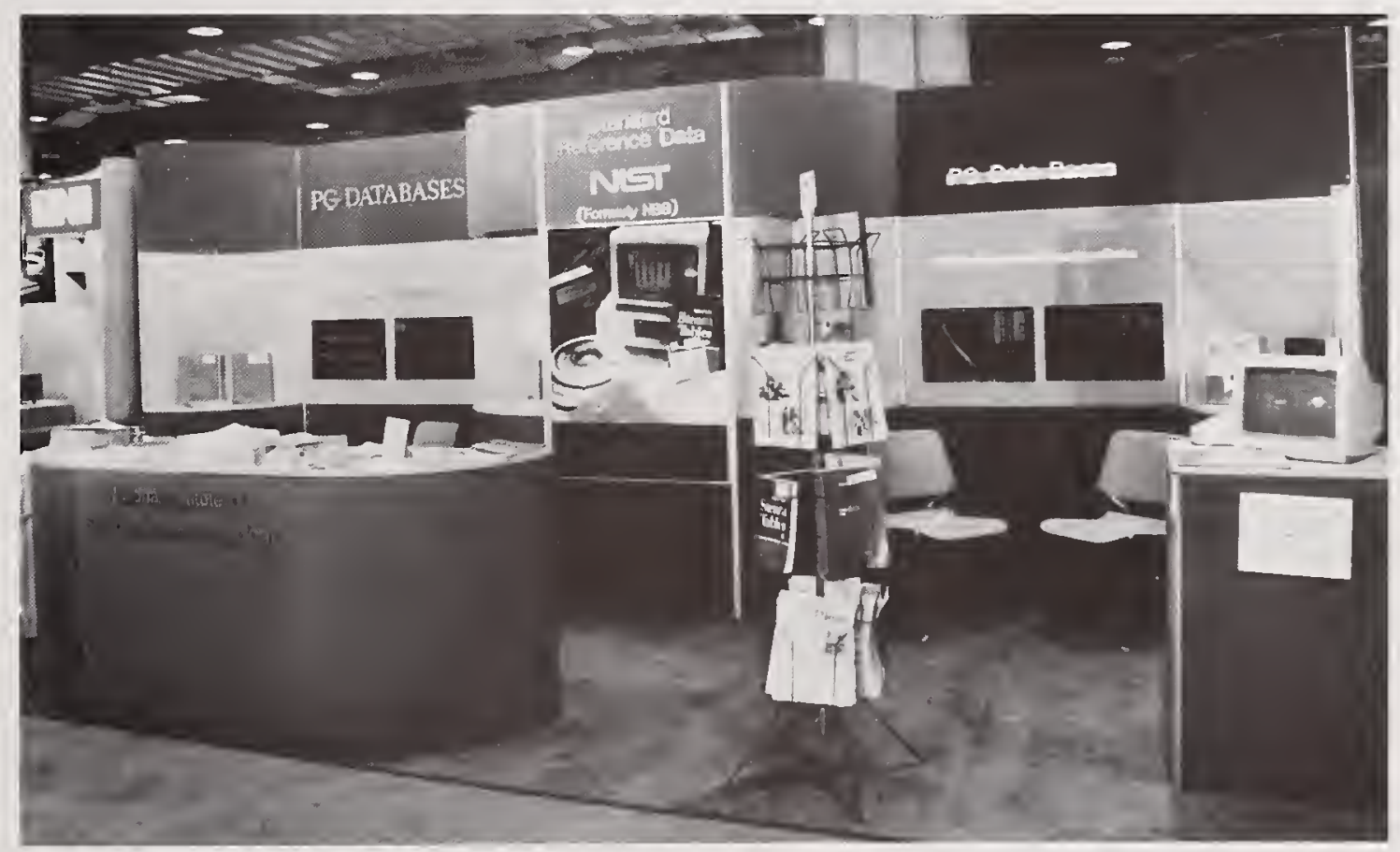

The Standard Reference Data booth appears at many scientific conferences and meetings. 


\section{TABLE OF CONTENTS}

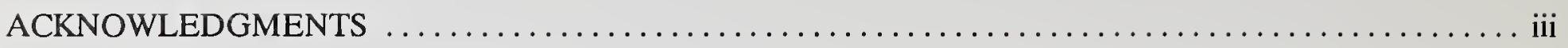

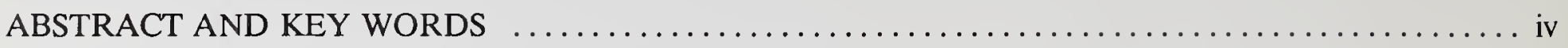

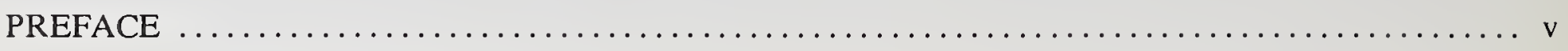

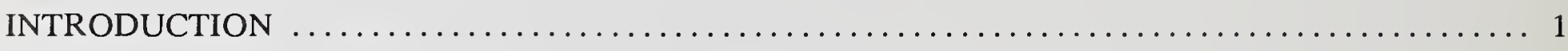

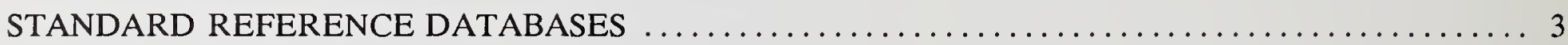

DATABASES AND PUBLICATIONS

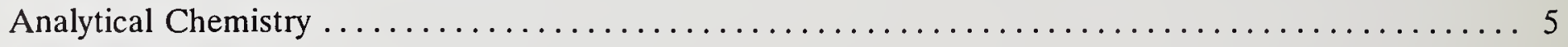

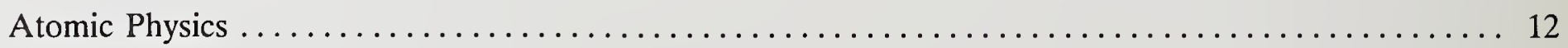

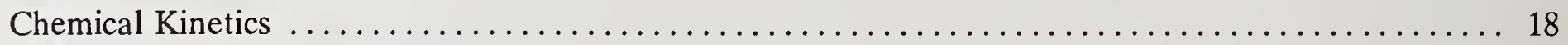

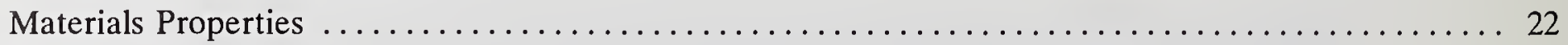

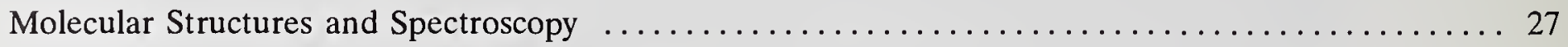

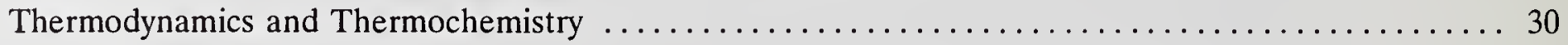

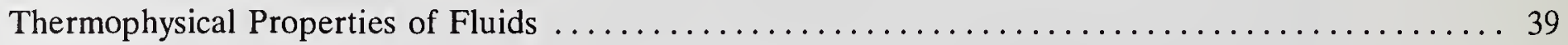

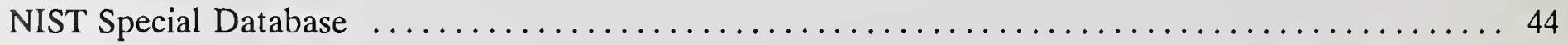

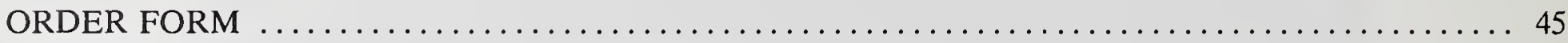




\section{INTRODUCTION}

The NIST Standard Reference Data (SRD) Program provides reliable, well-documented data to scientists and engineers for use in technical problem solving, research, and development.

Experts in the physical, chemical, and materials sciences critically evaluate data that result from experimental measurements, calculations, and theory. The evaluations are carried out through a network of data centers, projects, and cooperative programs that comprise the National Standard Reference Data System (NSRDS).

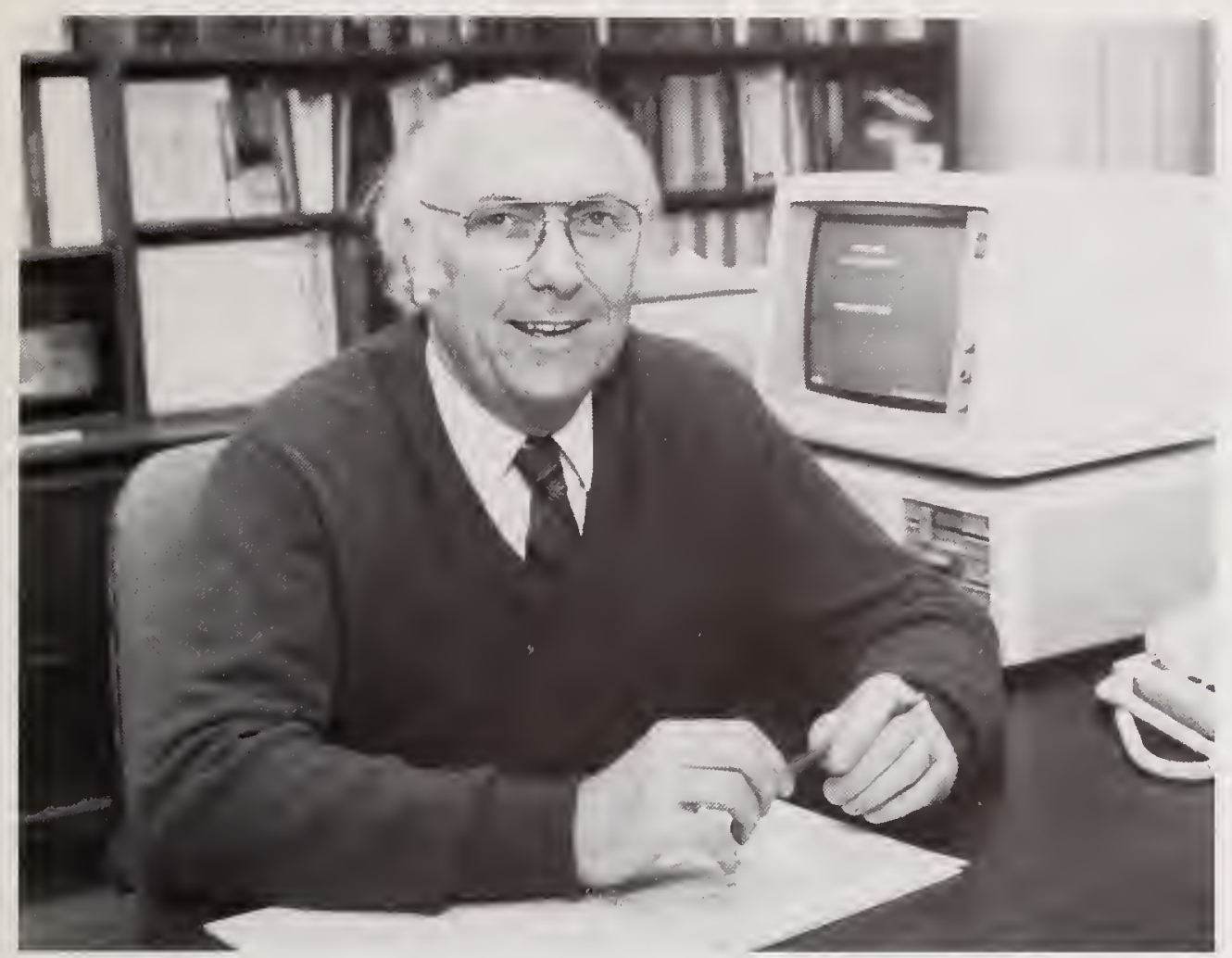

Experienced researchers in each area assess the accuracy of the data reported in the literature, prepare compilations, and recommend best values. The outputs are widely distributed as publications and computer-readable databases.

Current activities in the Standard Reference Data Program are carried out in long-term data centers, located primarily at NIST, and numerous short-term projects, primarily at universities and industrial research centers. In addition, the Program maintains many long-term collaborations with industry on cooperative data programs which draw support from industry and government.

Dr. Malcolm W. Chase, Jr. is Chief of the Standard Reference Data Program.

The activities concentrate on the disciplines as follows:

Analytical Chemistry - includes mass spectral data, surface analysis data, and crystallographic data for chemical identification.

Atomic Physics - includes atomic energy levels, transition probabilities, and collision data used for characterization and modeling.

Chemical Kinetics - includes evaluated data on gas phase reactions.

Materials Properties - structure and characterization of materials, performance properties, including corrosion, mechanical and tribology, and phase equilibria.

Molecular Structures and Spectroscopy - evaluated data on structures of molecular data.

Thermodynamics and Thermochemistry - includes reliable, widely-used tables of organic and inorganic species.

Thermophysical Properties of Fluids - thermophysical properties of pure and mixed fluids that are of great importance to industry. 
The data collections resulting from this work are disseminated in different ways:

National Standard Reference Database Series - Databases on diskettes, magnetic tapes, and online systems. Journal of Physical and Chemical Reference Data - A bimonthly Journal published jointly with the American Chemical Society and the American Institute of Physics.

NIST Publication Series - Various technical report series published by NIST.

Other joint publications - Journals and books published with technical society and private publishers.

When ordering an SRD database, checks, purchase orders, Visa, and Mastercard are accepted. Orders can be placed by phone or FAX for quick turn-around. For further information on SRD databases, please contact:

Joan Sauerwein

Standard Reference Data

National Institute of Standards and Technology

Bldg. 221/Room A320

Gaithersburg, MD 20899

(301) $975-2208$

(301)926-0416 (FAX)

The Standard Reference Data Distribution Group, (l to r) Cheryl Williams, Joan Sauerwein, and Sherena Johnson, market and distribute $S R D$ databases.

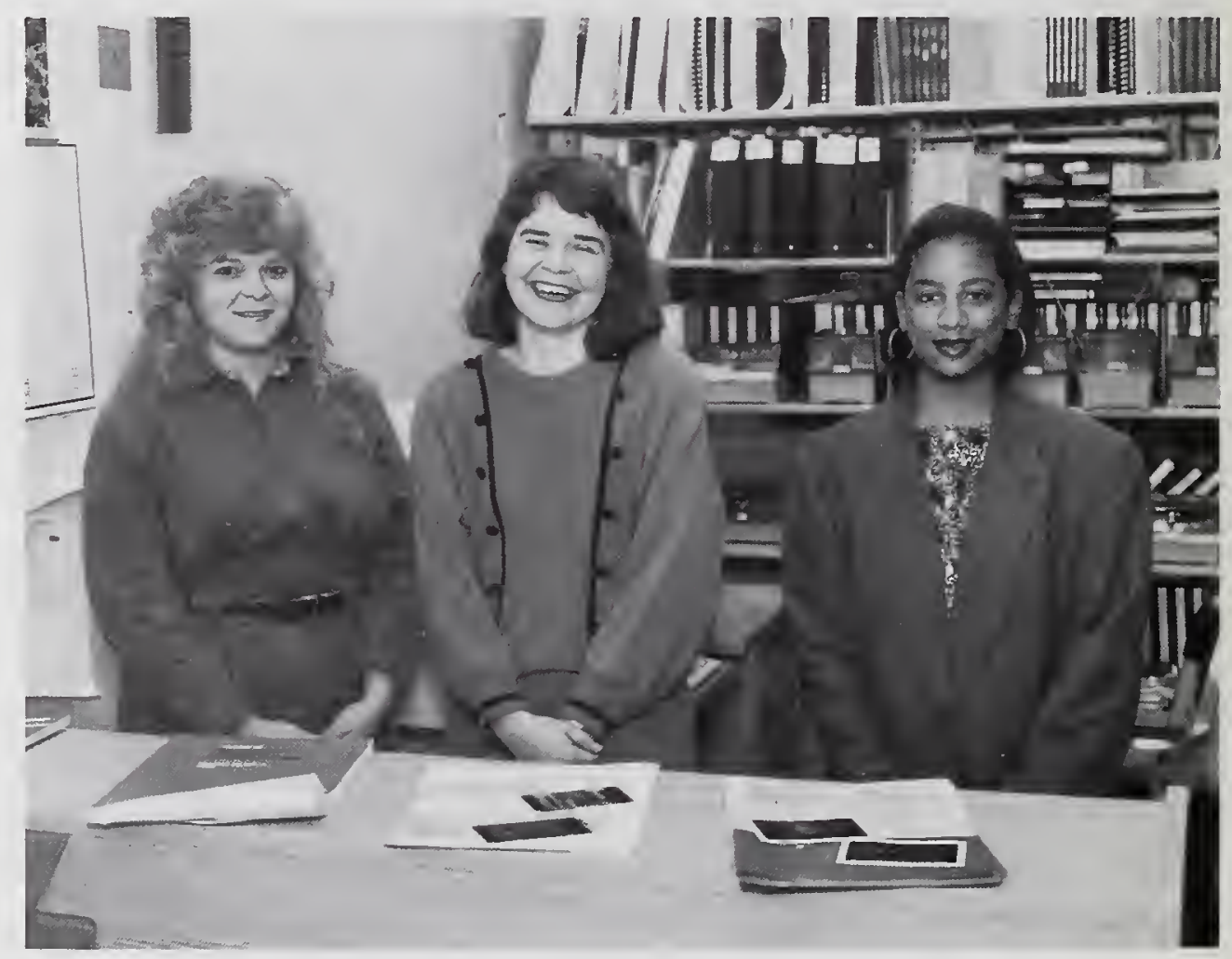




\section{STANDARD REFERENCE DATABASES}

1. NIST/EPA/MSDC Mass Spectral

1A. NIST/EPA/MSDC Mass Spectral: PC Version

1B. NIST Mass Spectral Database of Common Compounds

2. NIST Chemical Thermodynamics

3. NIST Crystal Data Identification

4. NIST Thermophysical Properties of Hydrocarbon Mixtures

7. NIST Electron and Positron Stopping Powers of Materials

8. NIST X-ray and Gamma-ray Attenuation Coefficients and Cross Sections

9. NIST Activity and Osmotic Coefficients of Aqueous Electrolyte Solutions

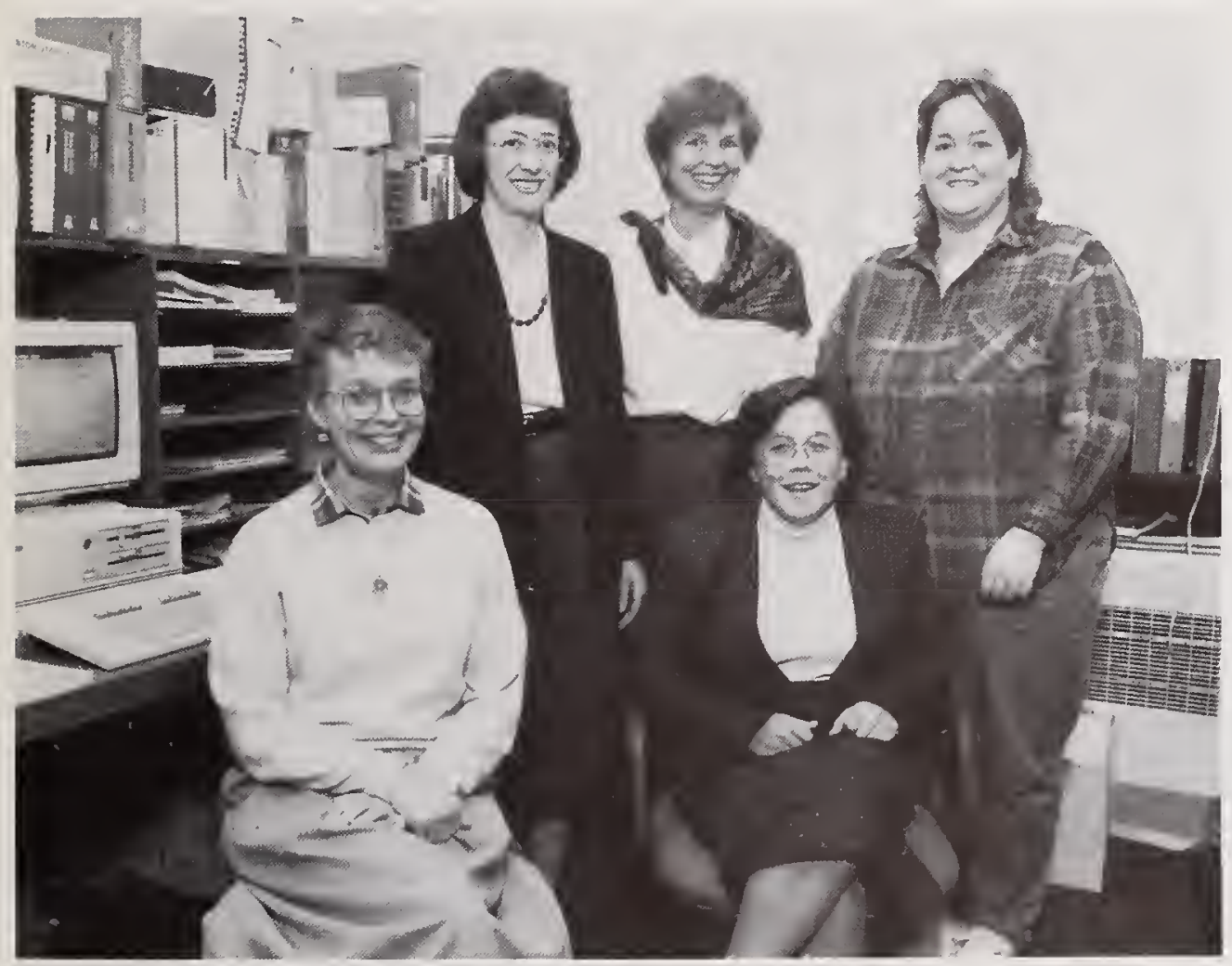

The SRD Data Systems Development Group, (seated l to r) Phoebe Fagan, Shari Young (standing l to r) Dorothy Bickham, Gerry Dalton, and Mary Dal-Favero, programmers of $S R D$ databases.

10. NIST Thermophysical Properties of Water

11. DIPPR Data Compilation of Pure Compound Properties

11A. Student Version of DIPPR Data Compilation of Pure Compound Properties

12. NIST Thermophysical Properties of Fluids

13. NIST JANAF Thermochemical Tables

14. NIST Mixture Property

15. NIST/Sandia/ICDD Electron Diffraction

16. NIST Corrosion Performance

17. NIST Chemical Kinetics

18. NIST Estimation of Thermodynamic Properties for Organic Compounds at $298.15 \mathrm{~K}$ Part 1. Hydrocarbons 


\section{STANDARD REFERENCE DATABASES (continued)}

19AB. NIST Positive and Negative Ion Energetics

20. NIST X-ray Photoelectron Spectroscopy

21. NIST/CARB Biological Macromolecule Crystallization

22. Tribomaterials I

23. NIST Thermodynamic Properties of Refrigerants and Refrigerant Mixtures

24. NIST Atomic Transition Probabilities

26. NIST Vibrational and Electronic Energy Levels of Small Polyatomic Transient Molecules

30. NIST Structural Ceramics

31. NIST Phase Diagrams for Ceramists

The Bedford Composition Group Judy Calabrese (l) and Connie Seymour, electronic typesetters for the Journal of Physical and Chemical Reference Data.

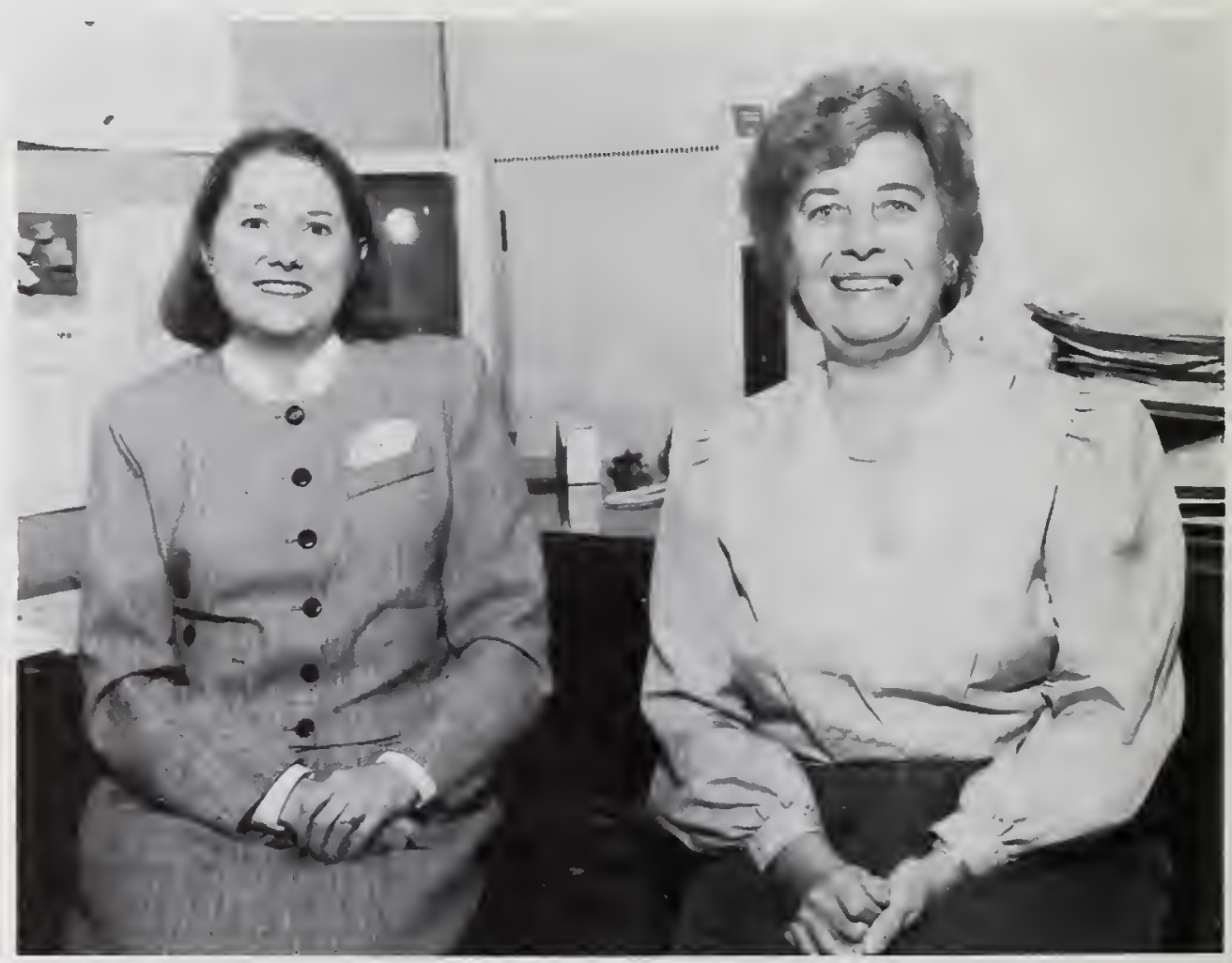

NIST Special Database

1. NIST Binary Images of Printed Digits, Alphas, and Text 
In the field of analytical chemistry, the SRD Program provides a set of comprehensive, easy-to-use databases and printed data compilations that help the analytical chemist identify unknown materials, and in many cases, once identified, avoid the need to recharacterize a substance. SRD databases cover a full range of analytical techniques, including mass spectrometry, surface analysis, and crystallographic structure.

To reach the greatest possible audience, the data collections are offered in several formats; as PC diskettes, on magnetic tape for inclusion in in-house laboratory systems, as incorporated into instruments themselves, and via online database systems.

In every case, the data have been fully evaluated, using a variety of techniques. When appropriate, duplicate measurements have been included for completeness. All the databases are updated on a regular basis. The PC diskette version of these databases includes an easy-to-use interface that can be mastered quickly and without having to resort to large manuals.

The NIST/EPA/MSDC Mass Spectral Database continues to reach an ever-widening audience as it is improved and expanded and stands alone as the only database which fulfills EPA requirements for use in characterizing "tentatively identified compounds."

\title{
SRD Analytical Chemistry Databases
}

\author{
Mass Spectra \\ NIST/EPA/MSDC Mass Spectral Database \\ NIST/EPA/MSDC Mass Spectral Database: PC Version \\ NIST Mass Spectral Database of Common Compounds \\ Crystallization Data \\ NIST Crystal Data Identification File \\ NIST/CARB Biological Macromolecule Crystallization Database

\section{Diffraction Data} \\ NIST/Sandia/ICDD Electron Diffraction Database

\section{Surface Data} \\ NIST X-ray Photoelectron Spectroscopy Database
}

\section{SRD Major Publications in Analytical Chemistry}

The Wiley/NBS Registry of Mass Spectral Data

Crystal Data Determinative Tables (6 vols.)

Elemental and Interplanar Spacing Index 


\title{
ANALYTICAL CHEMISTRY DATABASES
}

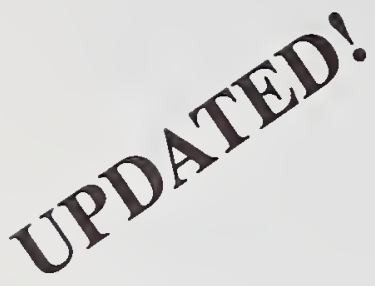

\section{NIST/EPA/MSDC Mass Spectral Database 1990 Version}

\author{
Sharon G. Lias \\ Mass Spectrometry Data Center \\ National Institute of Standards and Technology \\ Gaithersburg, MD 20899 \\ (301) $975-2562$
}

The NIST/EPA/MSDC Mass Spectral Database has been assembled from a variety of sources in a joint program of the Environmental Protection Agency, the National Institutes of Health, the United Kingdom Mass Spectrometry Data Center, and the National Institute of Standards and Technology.

The database contains ionization mass spectra of 53,994 different compounds. Each spectrum has a "quality index" associated with it, the Chemical Abstracts Service (CAS) name, synonyms, the molecular weight and formula, and the CAS registry number. Structures have recently been included for 97 percent of the spectra. Categories of substances identified are steroids, alkaloids, drugs, derivatives, amino acids, metals, carbohydrates, fatty acids and lipids, pesticides, and primary pollutants. This is the only database which fulfills EPA requirements for use in characterizing "tentatively identified compounds."

This database is available as a magnetic tape, both in an ASCII and a Binary Version. It is widely used in the mass spectrometers of many commercial instrument manufacturers.

\section{A. NIST/EPA/MSDC Mass Spectral Database: PC Version 3.0}

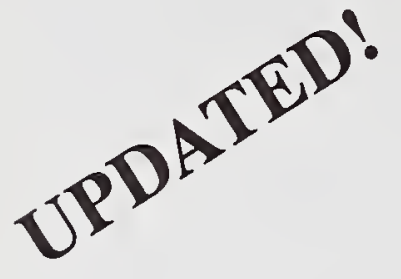

\author{
Stephen E. Stein \\ Mass Spectrometry Data Center \\ National Institute of Standards and Technology \\ Gaithersburg, MD 20899 \\ (301) $975-2505$
}

The PC Version of the NIST/EPA/ MSDC Mass Spectral Database was released in September 1987. Version 2.0 was released in December 1988 and Version 3.0 was released in June 1990. This database consists of 53,994 electron ionization mass spectra (with structures for over 52,000 compounds), various index files for rapid data retrieval, and related software for searching the database in various ways.

Version 3.0 has many versatile display features.

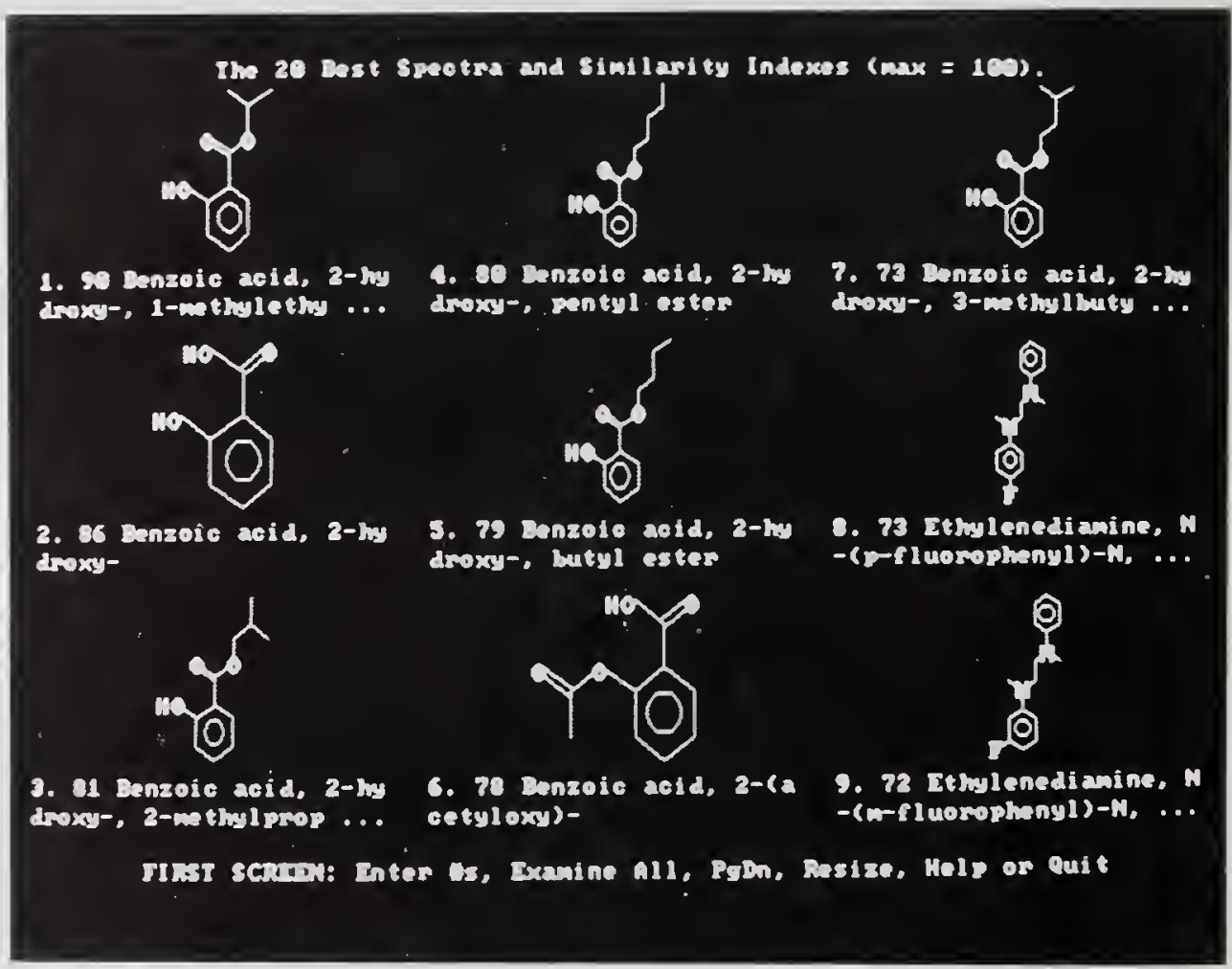


A quickly-learned interface allows the database to be searched by:

- identification number

- CAS registry number

- chemical name (including tens of thousands of alternative names)

- molecular formula

- molecular weight

- any peaks (up to 10 peaks with an intensity range for each)

- major peaks (up to 3 ordered peaks)

- your spectrum (choose quick, standard, or extensive search options)

Various display features are available:

- masses of major peaks

- expand scale

- autoscale

- dump to laser or dot matrix printer

- difference plots

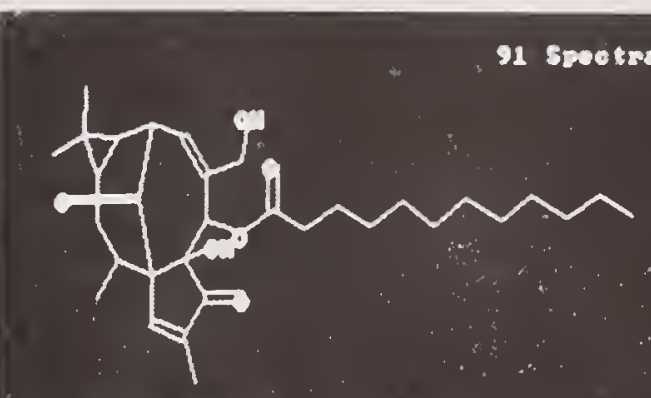

1. Dolecenoio acid, $10,2,5,52,5,9,10$,

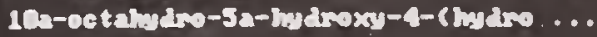

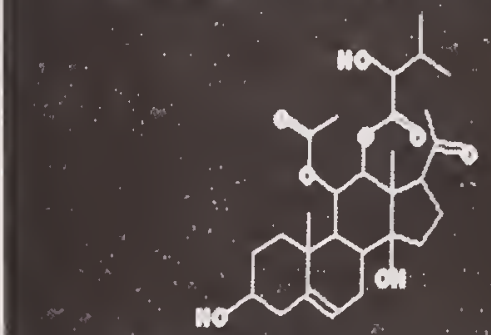

2. Presn-5-en-20-one, $11-(\operatorname{acotyloxy})-$ 3,14-dilestoxy-12-12-hydroxy-3-10 ...

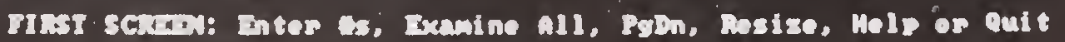

- spectrum scrolling

This important PC database provides a powerful tool for locating a particular spectrum or for identifying spectra of unknown compounds. Regular and frequent updates are planned. It comes in both AT and PS2 versions.

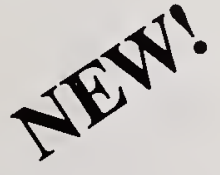

1B. NIST Mass Spectral Database of Common Compounds

\author{
Stephen E. Stein \\ Mass Spectrometry Data Center \\ National Institute of Standards and Technology \\ Gaithersburg, MD 20899
}

(301) $975-2505$

This version has the same rapid, sophisticated search software as the main database, but contains a smaller set of data, thus requiring only a fraction of the disk space needed for the full version. The data set has 10,330 spectra for important commercial compounds, as well as compounds of environmental or pharmaceutical interest. It comes in both AT and PS2 versions. 


\title{
3. NIST Crystal Data
}

\author{
Alan D. Mighell \\ Crystal Data and Electron Diffraction Center \\ National Institute of Standards and Technology \\ Gaithersburg, MD 20899 \\ (301) 975-6254
}

This database contains chemical, physical, and crystallographic information useful to characterize more than 154,000 inorganic and organic crystalline materials. The data include the standard cell parameters, cell volume, space group number and symbol, the calculated density, classification by chemical type, chemical formula, and chemical name. Each entry has an associated literature reference.

The database can be utilized as a practical analytical tool for compound identification because the lattice/formula combination uniquely characterizes a crystalline phase. The database is useful in conjunction with other data for materials design and properties prediction.

The file includes reliable data across the entire spectrum of the solid state including inorganics, organics, minerals, intermetallics, metals, alloys, drugs, antibiotics, and pesticides. Comprehensive chemical, crystallographic, and identification search software is provided with the database.

This database is available in magnetic tape and CD ROM formats. For further information, please contact International Centre for Diffraction Data, 1661 Park Lane, Swarthmore, PA 19081. Phone: (215) 328-9400.

\section{NIST/Sandia/ICDD Electron Diffraction Database}

\author{
Alan D. Mighell \\ Crystal Data and Electron Diffraction Center \\ National Institute of Standards and Technology \\ Gaithersburg, MD 20899
}

(301) 975-6254

This database is designed for phase characterization obtained by electron diffraction methods. The database and associated software permit highly selective identification procedures for microscopic, as well as macroscopic, crystalline materials. The database contains chemical, physical, and crystallographic information on a wide variety of materials (over 70,000) including minerals, metals, intermetallics, and general inorganic compounds.

The Electron Diffraction Database has been designed to include all the data required to identify materials using computerized $d$-spacing/formula matching techniques. The data for each entry include the conventional cell, reduced cell, lattice type, space group, calculated or observed d-spacings, chemical name, chemical and empirical formula, material class indicators, references, and other parameters.

This database and search software are available in magnetic tape format and in CD ROM format. In addition, it may be searched interactively via CISTI's online international service. For further information, please contact International Centre for Diffraction Data, 1661 Park Lane, Swarthmore, PA 19081. Phone: (215) 328-9400. 
20. NIST X-ray Photoelectron Spectroscopy Database

\author{
Cedric Powell \\ Surface Data Center \\ National Institute of Standards and Technology \\ Gaithersburg, MD 20899
}

(301) 975-2534

The NIST X-ray Photoelectron Spectroscopy (XPS) Database gives easy access to photoelectron and Auger spectral data. The database contains over 13,000 line positions, chemical shifts, and splittings resulting from a critical evaluation by Dr. Charles Wagner of the published literature through 1985 . The user may search by element, line type, line energy, and many other variables. Users can easily identify unknown measured lines by matching to all previous measurements.

RIGHT: The XPS Database makes photoelectron and Auger spectral data easily accessible.

BELOW: Dorothy Bickham, programmer of the XPS Database, demonstrates its features for Cheryl Williams (l) and Deborah Justus.

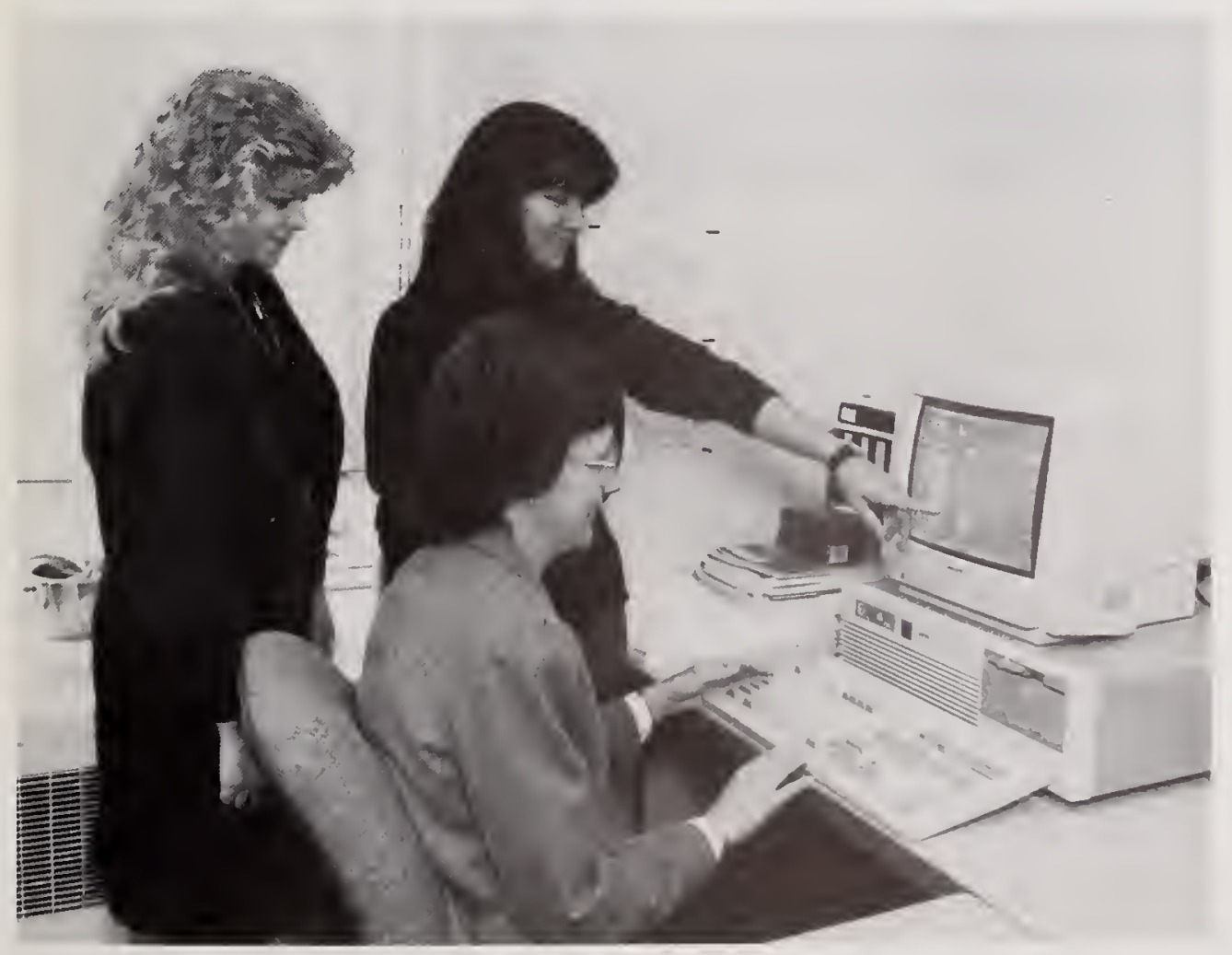

Each record on the database contains:

- Element and chemical compound, including names and formulas;

- Line type, i.e., photoelectron, Auger, Auger parameter, chemical shift, doublet splitting, other splittings;

- Line energy or energy difference;

- Experimental details such as calibration, charge reference, and physical state; and

- Reference citation.

This database is available in AT and PS2 versions. Updates are regularly scheduled. 


\title{
21. NIST/CARB Biological Macromolecule Crystallization Database
}

\author{
Gary L. Gilliland \\ Center for Advanced Research in Biotechnology \\ National Institute of Standards and Technology \\ 9600 Gudelsky Drive \\ Rockville, MD 20850
}

(301) 251-2244

The NIST/CARB Crystallization Database contains crystallization conditions and unit-cell parameters of crystals of biological macromolecules which have been reported in the literature. The biological macromolecules include proteins, nucleic acids, protein:protein complexes, nucleic acid:nucleic acid complexes, protein:nucleic acid complexes, and viruses. This database provides a convenient method for verification that a particular biological macromolecule has been crystallized and the details for reproducing the crystallization procedure.

The general information compiled for each macromolecule includes the name(s), molecular weight, sub-unit composition, and the presence of prosthetic group(s).

Dr. Gary L. Gilliland, developer of the Biological Macromolecule Crystallization Database.

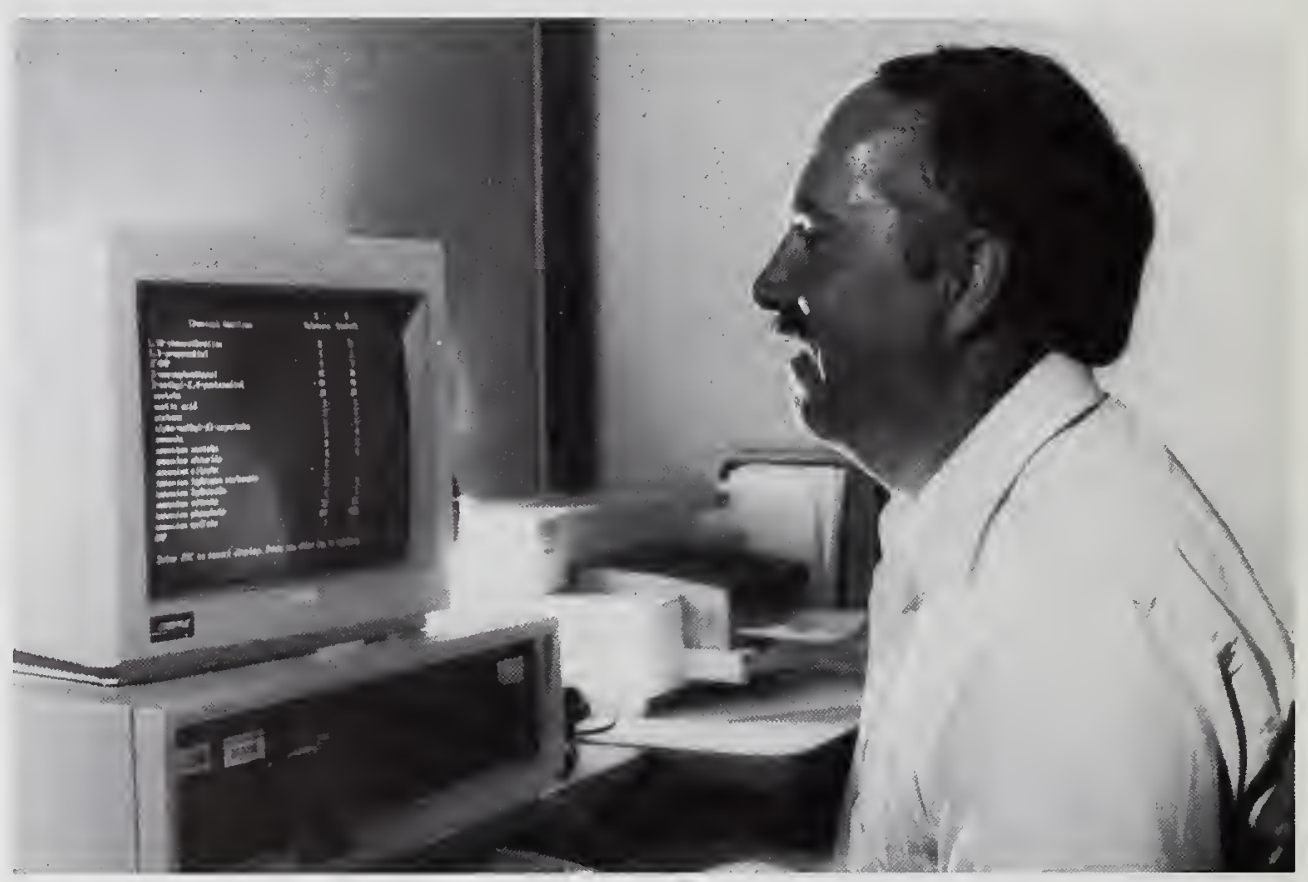

The description of the crystallization procedures consists of the macromolecular concentration, temperature, $\mathrm{pH}$, and growth time. If there are unique aspects to the crystallization procedure, they are described in detail. The crystal data include the space group, unit cell dimensions, $\mathrm{Z}$, crystal density, crystal habit, and size.

This database was developed at the Center for Applied Research in Biotechnology (CARB) and is available in $\mathrm{AT}, \mathrm{XT}$, and PS2 versions. 


\section{ANALYTICAL CHEMISTRY PUBLICATIONS}

The Wiley/NBS Registry of Mass Spectral Data - F. McLafferty and D. B. Stauffer. Wiley-Interscience, New York, 1988.

This 7-volume work combines mass spectra from the NIST/EPA/MSDC Mass Spectral Database and Wiley's Registry of Mass Spectral Data. It includes spectra of over 112,275 compounds, with structures for over 89,903 compounds. Substance names (CAS and common), molecular weights, empirical formula, and CAS registry numbers are provided. Spectra are arranged by ascending molecular weight, elemental composition, and type of compounds. In addition, complete indexing is given.

Available from Wiley-Interscience, NY. (212) 850-6000, $\$ 700.00$ (set price)

Crystal Data Determinative Tables, Third Edition -6 vols., International Centre for Diffraction Data, Swarthmore, PA.

The NIST Crystal Data Determinative Tables are the largest collection of crystallographic data available. These volumes contain data on over 43,000 organic and organometallic compounds, as well as 27,000 inorganic, metallic, and mineral compounds. Produced and edited by the NIST Crystal Data Center, these reference books are well-indexed by crystallographic system and determinative number. The data for each entry are comprehensive and include cell dimensions, space group or diffraction aspect, measured and calculated density, name, and literature reference.

Available from the International Centre for Diffraction Data, Swarthmore, PA. (215) 328-9400, $\$ 379.00$ (set price)

Elemental and Interplanar Spacing Index, International Centre for Diffraction Data, Swarthmore, PA.

The Elemental and Interplanar Spacing Index (EISI) is designed to be used independently or in conjunction with a computer database for phase characterization using electron or $\mathrm{x}$-ray diffraction. The EISI Index is arranged to enable the diffractionist to readily identify a material with the chemical and diffraction data routinely collected on most modern electron column instruments.

Available from the International Centre for Diffraction Data, Swarthmore, PA. (215) 328-9400, $\$ 250.00$ (set price) 


\section{ATOMIC PHYSICS}

The Standard Reference Data Program has worked together with the world-famous NIST Atomic Physics Program to produce the most comprehensive set of reliable atomic data available anywhere. The NIST collection of atomic energy levels, transition probabilities, and collision data are widely used by groups for characterizing and modeling all types of atomic systems, including plasmas, planetary atmospheres, astrophysical media, and health physics applications. Databases and publications make these data easy to find and easy to use.

In recent years, two important databases, one on electron and positron stopping powers and one on $\mathrm{x}$-ray and gamma-ray attenuation, have become widely used. The first computer file of NIST Atomic Transition Probability Data has become available and additional energy levels, transition probabilities, and collisions are also being converted into PC databases.

The SRD Atomic Data Program also is responsible for work on revision of the fundamental constants including release of the latest revision of 1986.

\section{SRD Atomic Databases}

NIST Electron and Positron Stopping Powers of Materials

NIST X-ray and Gamma-ray Attenuation Coefficients and Cross Sections

NIST Atomic Transition Probabilities Data Files (Scandium through Nickel)

\section{SRD Major Publications in Atomic Data}

Atomic Transition Probabilities

Atomic Energy Levels Publications

1986 CODATA Recommended Values of the Fundamental Physical Constants 


\title{
ATOMIC PHYSICS DATABASES
}

\section{NIST Electron and Positron Stopping \\ Powers and Ranges}

\author{
S. M. Seltzer \\ Photon and Charged Particle Data Center \\ National Institute of Standards and Technology \\ Gaithersburg, MD 20899
}

(301) 975-5552

The NIST Database on Electron and Positron Stopping Powers and Ranges provides rapid calculation of stopping powers (collisional, radiative, and total), CSDA ranges, radiation yields, and density effect corrections for incident electrons or positrons with kinetic energies from $1 \mathrm{keV}$ to $10 \mathrm{GeV}$, and for any chemically defined target material. The interactive database allows the user to specify an incident particle, an energy range, the target material, and density and for a gas, temperature, and pressure. Clear instructions make the calculations easy to perform. Results can be saved to an external file for future use.

This database is available in PC diskette format. A similar database available on magnetic tape extracts similar information for specific materials ( 285 for incident electrons and 29 for positrons).

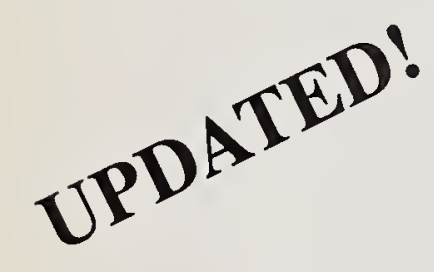

\section{NIST X-ray and Gamma-ray Attenuation Coefficients and Cross Sections}

\author{
S. M. Seltzer \\ Photon and Charged Particle Data Center \\ National Institute of Standards and Technology \\ Gaithersburg, MD 20899
}

(301) 975-5552

This database (called XGAM) provides photon cross sections (interaction coefficients) and attenuation coefficients for any substance. An interactive database is provided which enables the user to obtain data by entering chemical formulas or other measures of composition for a mixture of component materials. The user may also select the energy range over which data are desired.

The system operates from a database of cross sections for coherent and incoherent scattering, photoionization, and pair production for the elements $\mathrm{Z}=1$ to 100 at energies from $1 \mathrm{keV}$ to $100 \mathrm{GeV}$. These data were obtained by a critical data analysis combining theoretical and experimental results.

The user may request data to be tabulated at the fixed energies stored in the database, or at an arbitrary set of user-specified energies, or at a combination of both. The tabulated results include the individual contributions and the total mass attenuation coefficient, both with and without coherent scattering.

This database is available in PC diskette format. 
24. NIST Atomic Transition Probabilities Data Files

(Scandium through Nickel)

\author{
Jeffrey Fuhr \\ Atomic Transition Probabilities Data Center \\ National Institute of Standards and Technology \\ Gaithersburg, MD 20899 \\ (301) $975-3204$
}

This diskette package provides computer access to the numerical data given in "Atomic Transition Probabilities, Scandium Through Manganese" and "Atomic Transition Probabilities, Iron Through Nickel," which were published as Supplements 3 and 4 to Volume 17 (1988) of the Journal of Physical and Chemical Reference Data. The diskettes contain two types of files: the numeric files containing the transition probabilities and related data, and the bibliographic files of references pertaining to the numeric tables. There are separate numeric and bibliographic files for each of the eight elements from scandium through nickel. Within each element, the data files are ordered by the ionization stage.

This database is available in AT, XT, and PS2 versions.

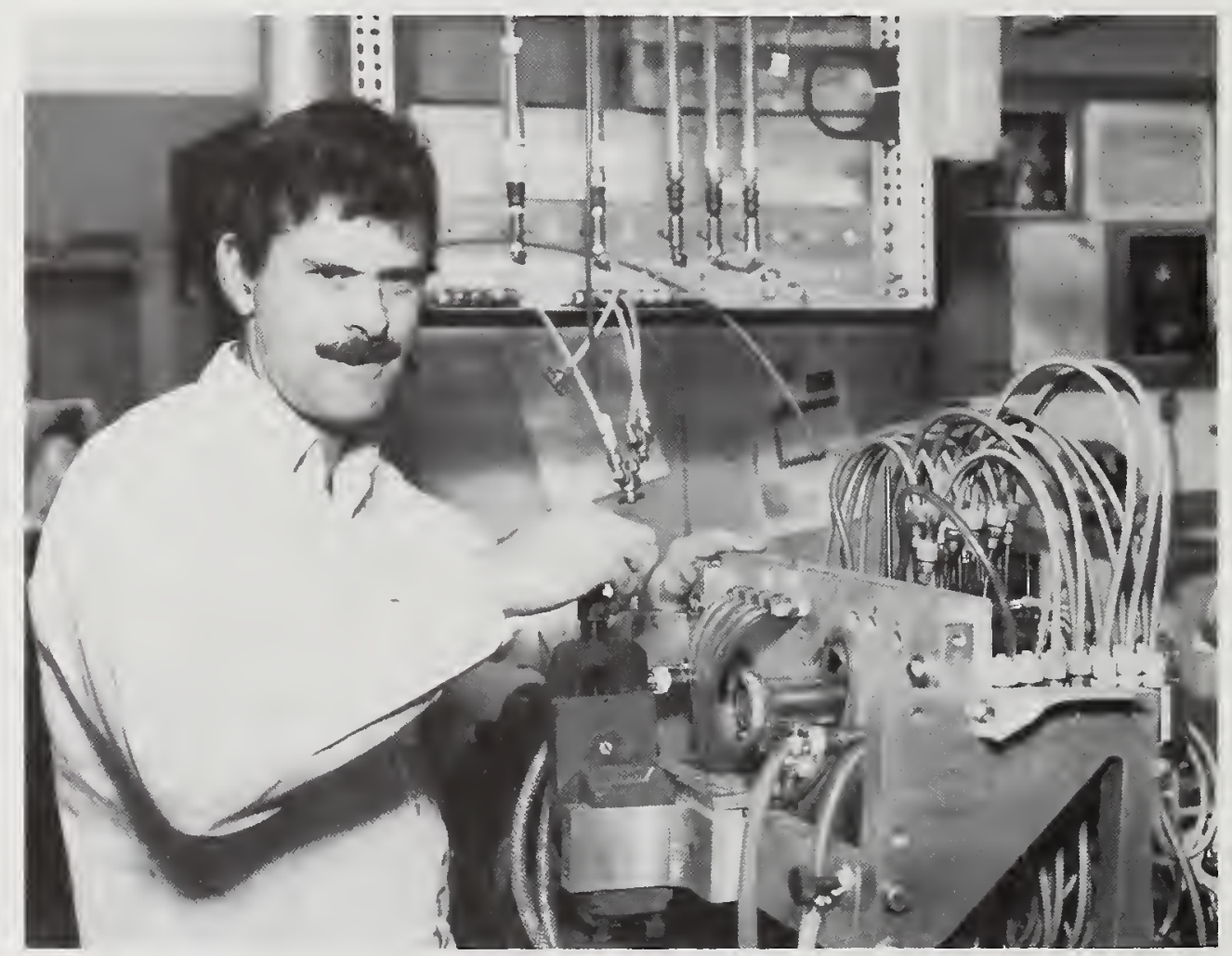

Jeffrey Fuhr demonstrates the use of a wall-stabilized arc to determine atomic transition probabilities. 


\section{ATOMIC PHYSICS PUBLICATIONS}

The 1986 CODATA Recommended Values of the Fundamental Physical Constants - E. Richard Cohen and Barry N. Taylor. Journal of Physical and Chemical Reference Data 17, 1795 (1988).

This article presents values of the basic constants and conversion factors of physics and chemistry resulting from the 1986 least-squares adjustment of the fundamental physical constants as recommended for international use by the CODATA (Committee on Data for Science and Technology) Task Group on Fundamental Constants. The 1986 CODATA set of values replaces the 1973 set also developed by CODATA.

Available from the American Chemical Society, Reprint 354, $\$ 5.00$

Atomic Transition Probabilities, Scandium Through Manganese - G. A. Martin, J. R. Fuhr, and W. L. Wiese. Journal of Physical and Chemical Reference Data 17, Supplement 3 (1988).

\author{
Atomic Transition Probabilities, Iron Through \\ Nickel - J. R. Fuhr, G. A. Martin, and W. L. \\ Wiese. Journal of Physical and Chemical Reference \\ Data 17, Supplement 4 (1988).
}
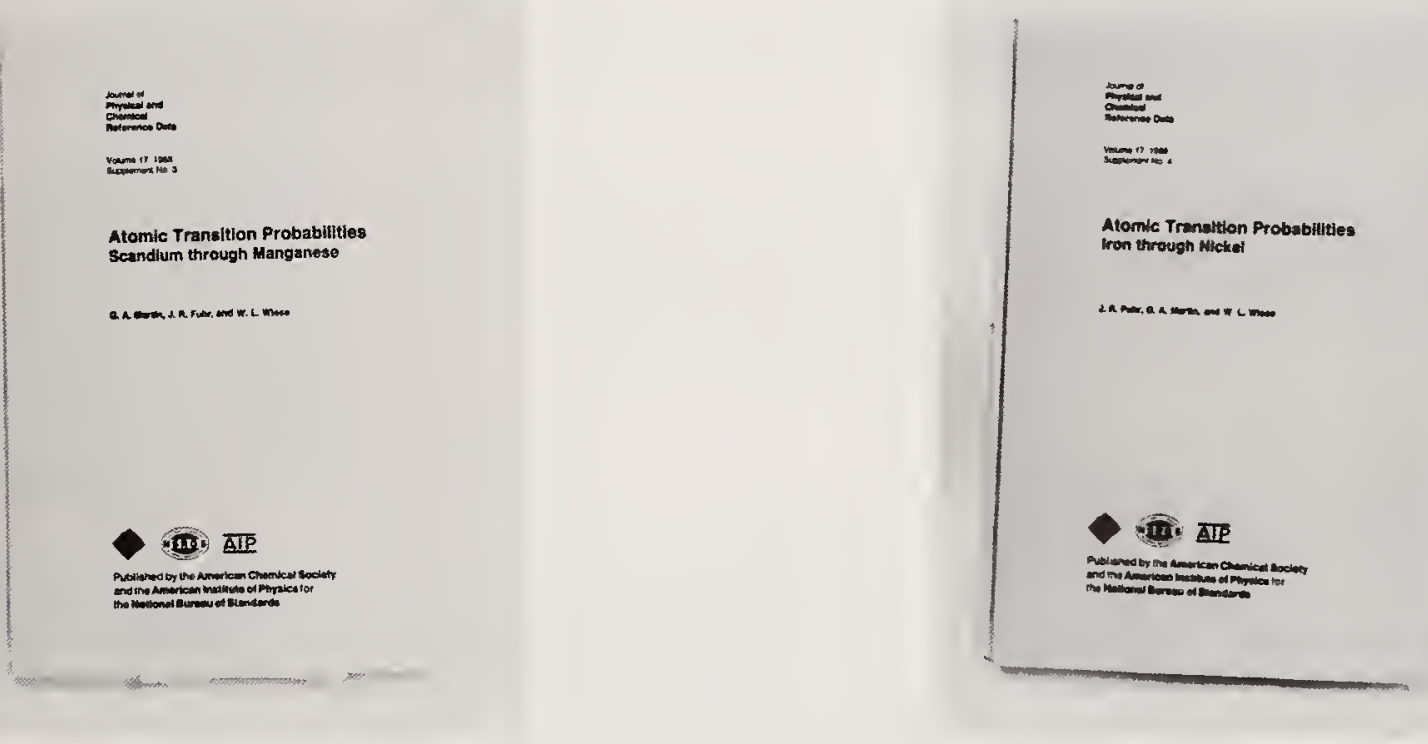

These two supplements to the Journal of Physical and Chemical Reference Data contain almost 18,000 atomic transition probabilities. With over 1,000 pages of tables and critical discussion, it is the first comprehensive reference source for the transition probabilities of the eight transition metals, scandium through nickel. The data in these two volumes are presented by element and spectrum. Finding lists are provided to facilitate transition location. The tables include spectroscopic classification, wavelengths of the transitions, the lower and upper energy levels, and their statistical weights. For each line, an uncertainty estimate, the result of careful, critical evaluation, is given.

Both available from the American Chemical Society

U.S. and Canada \$65.00 each

Abroad

$\$ 78.00$ each 
Atomic Energy Levels of the Iron-Period Elements: Potassium Through

Nickel - J. Sugar and C. Corliss. Journal of Physical and Chemical Reference Data 14, Supplement 2 (1985).

This supplement is a compilation of atomic energy levels of the iron-period elements, potassium through nickel, in all stages of ionization. The result of a critical evaluation of all literature published through 1985, it gives for each energy level the position relative to the ground state, configuration, term designation, J-value, and, where available, the g-value and the two leading percentages of the eigenvector composition in the most appropriate coupling scheme. This is an invaluable research tool for atomic, molecular, plasma, and astronomical scientists.

Available from the American Chemical Society

U.S. and Canada $\$ \mathbf{6 5 . 0 0}$

Abroad $\$ \mathbf{5 8 . 0 0}$

$=$

$\operatorname{tancising} 2$

Atomle Energy Levels of the Iron-Perlod Eloments:
Potasilum through Nickel

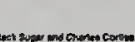

Energy Levels of Copper, Cu I through Cu XXIX - Jack Sugar and Arlene Musgrove. Journal of Physical and Chemical Reference Data 19, 527 (1990).

In this publication, the energy levels of the copper atom, in all stages of ionization for which experimental data exist, have been compiled. Ionization energies, either experimental or theoretical, and experimental g-factors are given. Leading components of calculated eigenvectors are listed.

Available from the American Chemical Society, Reprint 385, $\$ 10.00$

Energy Levels of Sulfur, S I through S XVI - W. C. Martin, Romuald Zalubas, and Arlene Musgrove. Journal of Physical and Chemical Reference Data 19, 821 (1990).

Energy level data are given for the atom and all positive ions of sulfur $(Z=16)$. These data have been critically compiled, mainly from published and unpublished material on measurements and analyses of the optical spectra. For a number of the ions, the levels have been derived or recalculated. Leading percentages from the calculated eigenvectors are tabulated or quoted wherever available, and ionization energies are given for all spectra.

Available from the American Chemical Society, Reprint 392, \$8.00

Spectral Data and Grotrian Diagrams for Highly Ionized Iron, Fe VIII - XXVI - Toshizo Shirai, Yoshio Funatake, Kazuo Mori, Jack Sugar, Wolfgang Wiese, and Yohta Nakai. Journal of Physical and Chemical Reference Data 19, 127 (1990).

Wavelengths, energy levels, level classifications, oscillator strengths, and atomic transition probabilities for the iron ions Fe VIII to Fe XXVI are critically reviewed and tabulated. Grotrian diagrams are also presented. Available from the American Chemical Society, Reprint 379, $\$ 14.00$

Cross Sections and Swarm Coefficients for $\mathrm{H}^{+}, \mathrm{H}_{2}{ }^{+}, \mathrm{H}_{3}{ }^{+}, \mathrm{H}, \mathrm{H}_{2}$, and $\mathrm{H}^{-}$in $\mathrm{H}_{2}$ for Energies from $0.1 \mathrm{eV}$ to 10 keV - A. V. Phelps. Journal of Physical and Chemical Reference Data 19, 653 (1990).

Graphical and tabulated data and the associated bibliography are presented for cross sections for elastic, excitation and ionization collisions. Where appropriate, drift velocities and reaction or excitation coefficients are calculated from the cross sections and recommended for use in analyses of swarm experiments and electrical discharges.

Available from the American Chemical Society, Reprint $388, \$ 6.00$ 
Experimental Stark Widths and Shifts for Spectral Lines of Neutral and Ionized Atoms (A Critical Review of Selected Data for the Period 1983 through 1988) - N. Konjevic and W. L. Wiese. Journal of Physical and Chemical Reference Data 19 (1990).

A critical review of the available experimental data on Stark widths and shifts for spectral lines non-hydrogenic neutral atoms and positive ions has been carried out. Data tables containing the selected experimental Stark broadening parameters are presented with estimated accuracies. The data are arranged according to elements and spectra, and these are presented in alphabetical and numerical order.

Available from the American Chemical Society, Reprint $\mathbf{4 0 2}$

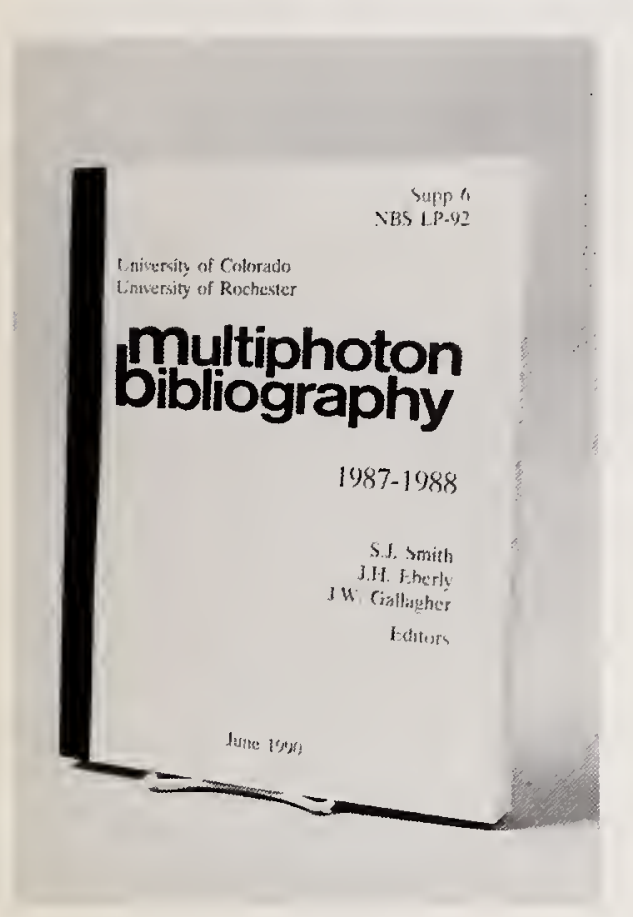

Multiphoton Bibliography 1983-1986 - S. J. Smith, J. H. Eberly, J. W. Gallagher, editors. NBS-LP-92, Suppl. 5 (June 1989).

This bibliography expands the collection of references describing studies of the interaction of more than one photon with individual atoms and molecules in the gas phase. Over 1,200 papers are included and classified into the categories of ionization, bound-bound, and dissociation by two-photons, three-photons and more than three photons. The papers are also indexed by target material. Available (no charge) from JILA Data Center, University of Colorado, Boulder, CO. (303) 492-7801

X-ray Attenuation Cross Sections for Energies $100 \mathrm{eV}$ to $100 \mathrm{keV}$ and Elements $\mathrm{Z}=1$ to $\mathrm{Z}=92-$ E. B. Saloman and J. H. Hubbell. Atomic Data and Nuclear Data Tables 38, 1 (1988).

In this work, the NIST database of experimental $x$-ray attenuation coefficients and cross sections for the energy range $0.1-100 \mathrm{keV}$ is calculated using a relativistic Hartree-Slater model for the photoelectric cross section for all elements of atomic number $Z=1-92$. The information is displayed in both tabular and graphic form. A bibliography of the NIST database for this energy range is included.

Available from Academic Press, NY. (212) 614-3000, order no. 0092-640X/88, $\$ 3.00$ 


\section{CHEMICAL KINETICS}

The NIST Program on Chemical Kinetics Data has long been a source of reliable, critically evaluated data on gas-phase reactions. Over the years, data provided by the program have been instrumental in modeling and predicting many important scientific problems such as combustion chemistry, atmospheric changes caused by ozone depletion and warming, plasmas, and free-radical chemistry.

Recently, a comprehensive, easy-to-use PC database on over 2,000 gas-phase reactions has been widely distributed allowing scientists quick access to reaction rate data, as well as supporting information. In addition, the Radiation Chemistry Data Center at Notre Dame University provides a biweekly literature current awareness service on kinetics of ions and free-radicals.

\section{SRD Chemical Kinetics Database}

NIST Chemical Kinetics Database

\section{SRD Major Publications in Chemical Kinetics}

Kinetics and Mechanisms of the Gas-Phase Reactions of the Hydroxyl Radical with Organic Compounds Biweekly List of Papers on Radiation Chemistry and Photochemistry Evaluated Chemical Kinetic Data for the Reactions of Atomic Oxygen $\mathrm{O}\left({ }^{3} \mathrm{P}\right)$ with Unsaturated Hydrocarbons Chemical Kinetic Data Base for Combustion Chemistry. Part 2. Methanol

Chemical Kinetic Data Base for Combustion Chemistry. Part 3. Propane

Chemical Kinetic Data Base for Combustion Chemistry. Part 4. Isobutane 


\title{
CHEMICAL KINETICS DATABASE
}

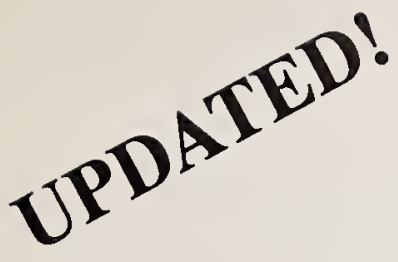

17. NIST Chemical Kinetics Database Version 2.0

\author{
W. Gary Mallard \\ Chemical Kinetics Data Center \\ National Institute of Standards and Technology \\ Gaithersburg, MD 20899 \\ (301) $975-2564$
}

The NIST Chemical Kinetics Database is designed to provide rapid access to kinetics data for gas-phase reactions. Searches provide a summary of all of the literature on a particular reaction, all of the reactions of a specific species, subsets of all of the reactions, and the data available from a given paper. Version 2.0 contains over 12,000 records, over 5,000 reactions, and over 2,400 compounds which are reactants or properties.

\section{Display Options}

- an increased number of leastsquare fits

- display options for $\mathrm{A} \mathrm{T}^{\mathrm{n}}$ or $\mathrm{A}(\mathrm{T} /$ $298)^{\mathrm{n}}$ and activation energies in $\mathrm{kcal} / \mathrm{mol}$ or $\mathrm{kJ} / \mathrm{mole}$, as well as $\mathrm{K}$

- rate at a single temperature displayed in summary sheets for instant comparison of data

- simultaneous display of abstracts and graphics

- user settings for the axis to allow data comparison

- context sensitive help screens, including graphics

\section{User Input}

- user can add data to be plotted and fit

- user can add extensive comments
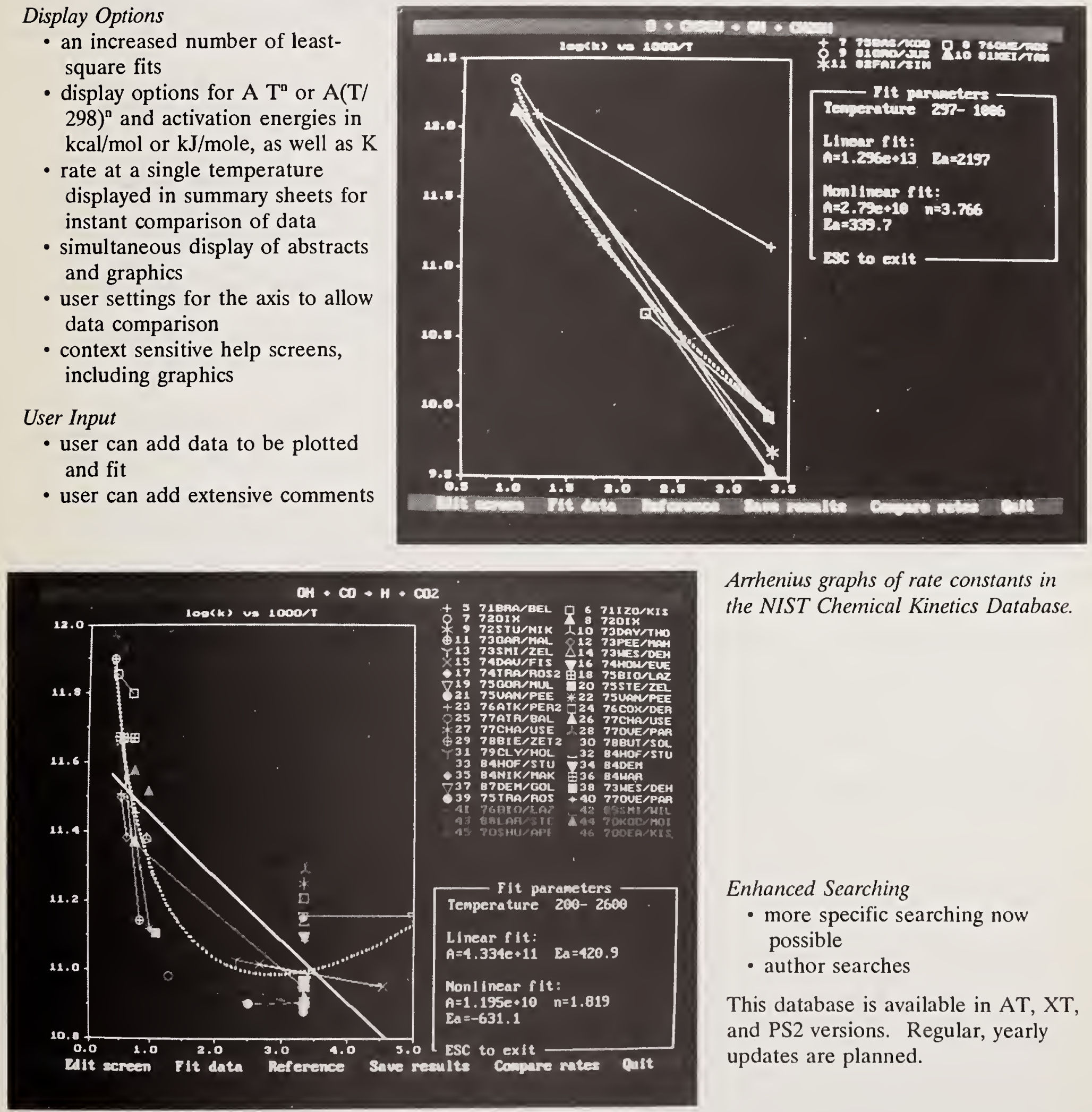

Arrhenius graphs of rate constants in the NIST Chemical Kinetics Database.

\section{Enhanced Searching \\ - more specific searching now possible \\ - author searches}

This database is available in AT, XT, and PS2 versions. Regular, yearly updates are planned. 


\section{CHEMICAL KINETICS PUBLICATIONS}

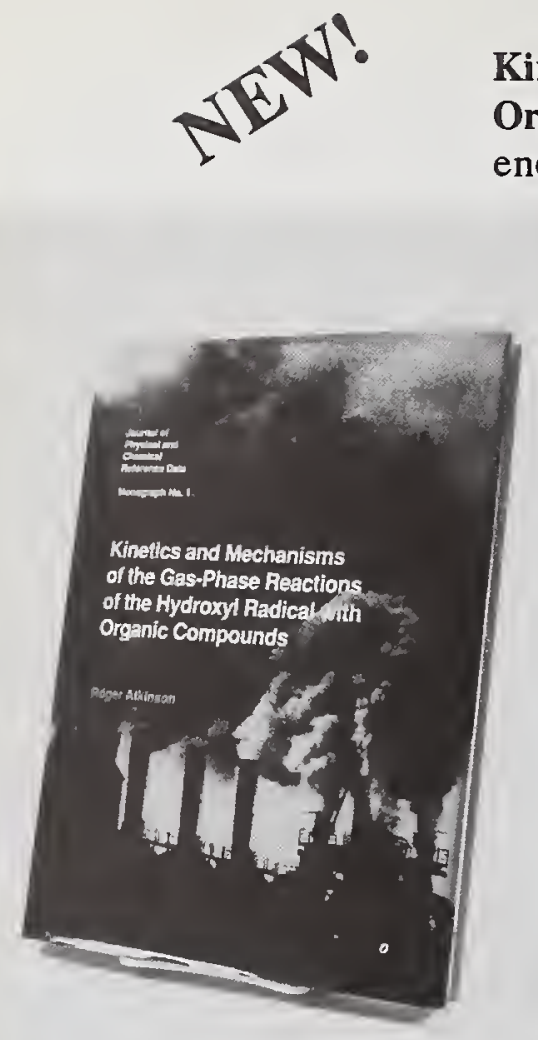

Kinetics and Mechanisms of the Gas-Phase Reactions of the Hydroxyl Radical with Organic Compounds - Roger Atkinson. Journal of Physical and Chemical Reference Data, Monograph 1 (1989).

This monograph reviews the entire literature through 1988 concerning the kinetics and mechanisms of gas-phase reactions of the hydroxyl radical with organic compounds and evaluates the data. Rate data for temperatures ranging from 220 to over $2000 \mathrm{~K}$ are included. Recommended rate expressions are given. Each recommendation is accompanied by text discussion, the available data, and the rationale behind the recommendation of best values. Also included are the estimated uncertainties in the recommended rate expression and discussions concerning the reaction mechanisms.

Available from the American Chemical Society

U.S. and Canada $\$ 55.00$

Abroad $\$ \mathbf{6 5 . 0 0}$

\section{Biweekly List of Papers on Radiation Chemistry and Photochemistry - Radiation Chemistry Data Center, Notre Dame, IN.}

This is a current-awareness publication with special emphasis on the kinetics and other properties of transient ions, radicals, and the excited species. $\mathrm{Pa}$ pers are included on the radiation chemistry and photochemistry of chemi-

cally-defined systems containing organic and inorganic compounds, biological molecules, and polymers, with references to ESR and luminescence studies. The references listed are obtained from scanning sixty current journals, as well as Chemical Abstracts, INIS Atomindex, and other publications.

Available from Radiation Chemistry Data Center, Radiation Laboratory, University of Notre Dame, Notre Dame, IN. \$42.00/year

Chemical Kinetic Data Base for Combustion Chemistry. Part 2. Methanol - Wing Tsang. Journal of Physical and Chemical Reference Data 16, 471 (1987).

This publication contains evaluated and estimated data on the kinetics of reactions involving methanol and hydroxymethyl radicals and various small inorganic and organic species which are of importance for methanol combustion of pyrolysis.

Available from the American Chemical Society, Reprint 327, $\$ 7.00$

Chemical Kinetic Data Base for Combustion Chemistry. Part 3. Propane - Wing Tsang. Journal of Physical and Chemical Reference Data 17, 887 (1988).

With evaluated and estimated data on the kinetics of reactions involving propane, isopropyl radical, n-propyl radical, and various small inorganic and organic species, this publication is important for propane pyrolysis and combustion.

Available from the American Chemical Society, Reprint $\mathbf{3 4 4 , \$ 9 . 0 0}$ 
Chemical Kinetic Data Base for Combustion Chemistry. Part 4. Isobutane - Wing Tsang. Journal of Physical and Chemical Reference Data 19, 1 (1990).

This publication contains evaluated and estimated data on the kinetics of reactions involving isobutane, t-butyl radical, and isobutyl radical and various small inorganic and organic species which are of importance for the proper understanding of isobutane combustion and pyrolysis.

Available from the American Chemical Society, Reprint 374, \$9.00

Rate Constants for Reactions of Peroxyl Radicals in Fluid Solution - P. Neta and Robert E. Huie. Journal of Physical and Chemical Reference Data 19, 413 (1990).

Absolute rate constants for reactions of alkylperoxyl and substituted alkylperoxyl radicals with inorganic and organic compounds in aqueous and non-aqueous fluid solutions were compiled. The radicals have been generated by radiolysis or photolysis and their rate constants were determined generally by kinetic spectrophotometry or esr.

Available from the American Chemical Society, Reprint 384, \$10.00 


\title{
MATERIALS PROPERTIES
}

The NIST Materials Data Program provides evaluated data on phase equilibria, structure, characterization, and performance properties.

The NIST/American Ceramics Society Program for Phase Diagrams for Ceramists has for many years published the authoritative sources for these data and has added a new database to supplement its nine volume series. The Binary Alloy Phase Diagram Program jointly sponsored by NIST and ASM International has completed its work to evaluate all binary alloy phase diagrams. A major new compendium has just been published.

Several materials performance property databases are available. The new NIST Structural Ceramics Database contains the most current data for various silicon carbides and silicon nitrides. It is the first structural ceramics database publicly available. Corrosion data (in conjunction with the National Association of Corrosion Engineers) and tribology data (together with ACTIS, Inc.) have been evaluated, and several databases produced by these programs have gained wide acceptance.

Crystallographic, electron diffraction, and surface analysis databases are also available and described in more detail under Analytical Chemistry.

\section{NIST Materials Properties Databases}

\author{
NIST Structural Ceramics \\ NIST Phase Diagrams for Ceramists \\ NACE-NIST Corrosion Performance Databases \\ COR*SUR 1 - Corrosion Rate Data for Metals \\ COR*SUR 2 - Corrosion Rate Data for Non-Metals \\ COR*DATA - Corrosion Database Management \\ NIST Crystal Data \\ NIST/Sandia/ICDD Electron Diffraction \\ NIST X-ray Photoelectron Spectroscopy \\ ACTIS Tribomaterials I
}

\section{SRD Major Publications in Materials Properties}

Journal of Phase Equilibria (formerly Bulletin of Alloy Phase Diagrams)

Phase Diagrams for Ceramists

Binary Alloy Phase Diagrams, 2nd edition 


\title{
MATERIALS PROPERTIES DATABASES
}

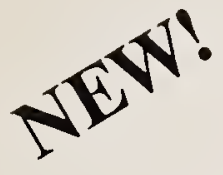

\author{
30. NIST Structural Ceramics Database \\ Ronald Munro/E. F. Begley \\ Ceramics Division \\ National Institute of Standards and Technology \\ Gaithersburg, MD 20899
}

(301) $975-6118$

This new and unique database contains thermal and mechanical properties of silicon carbides and silicon nitrides in a stand-alone, user-friendly system that operates on PCs.

Primary properties in the Structural Ceramics Database:

Materials Specification

- Name

- Formula

- Chemical Composition

- Fabrication

- Physical Properties

- Microstructural Information

- Processing

\section{Thermal Properties}

- Conductivity

- Diffusivity

- Expansion

- Specific Heat

- Shock Resistance

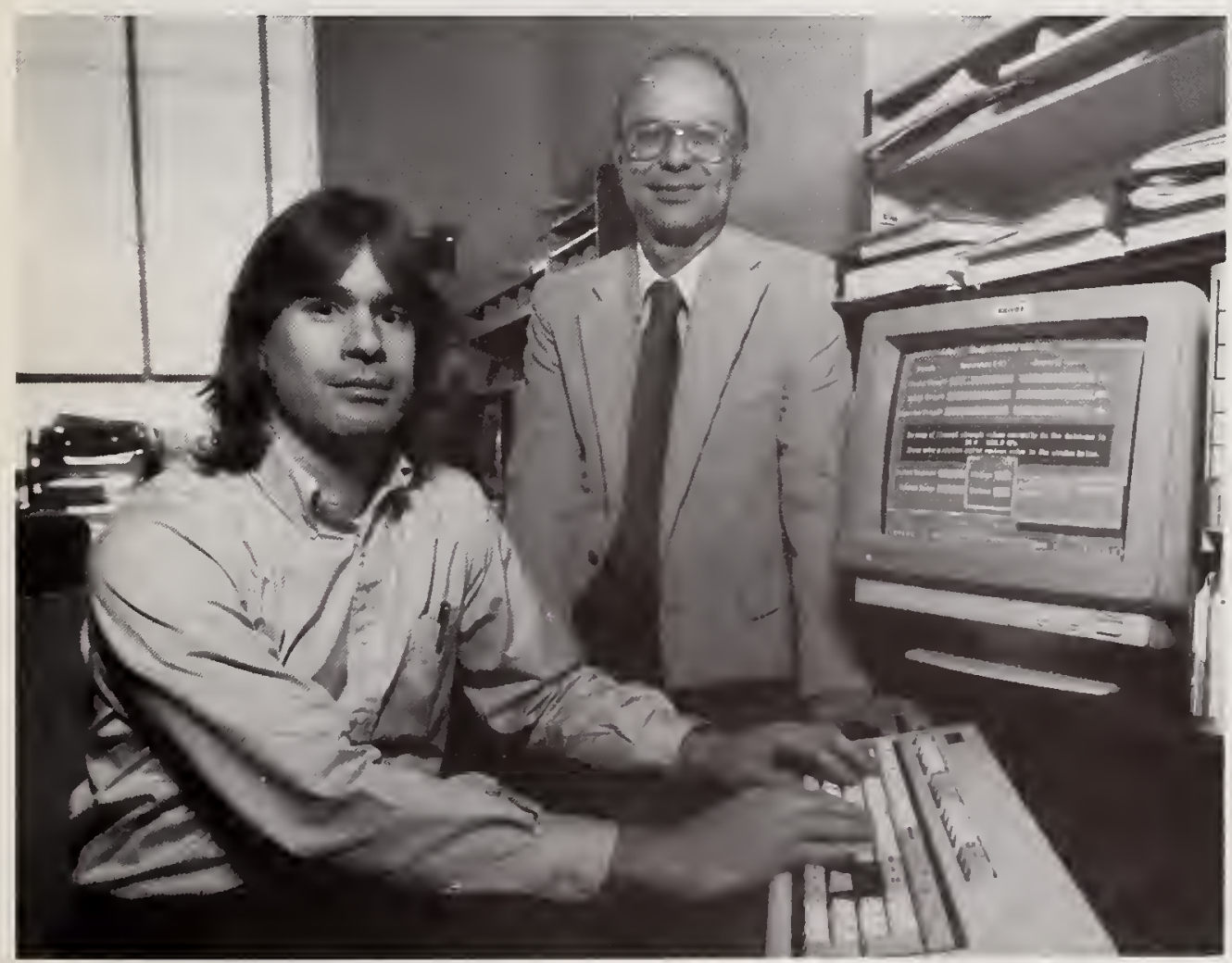

Mechanical Properties

- Elastic Modulus

- Poisson's Ratio

- Flexural Strength

- Tensile Strength

- Compressive Strength

- Vicker's Hardness

- Knopp Hardness

- Fracture Toughness

- Fracture Energy

- Weilbus Modulus

- Creep Exponent
Measurement Methods

- Specimen Preparation

- Apparatus

- Procedures

Bibliography

- Complete documentation of data sources through 1990

This database comes in AT and PS2 versions.
Ed Begley (l) and Dr. Ron Munro developed the new NIST Structural Ceramics Database. 


\title{
31. Phase Diagrams for Ceramists Database
}

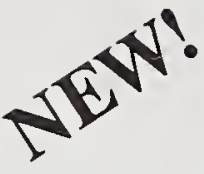

\author{
Helen Ondik \\ Phase Diagrams for Ceramists Data Center \\ National Institute of Standards and Technology \\ Gaithersburg, MD 20899 \\ (301) $975-6115$
}

This PC package provides computer access to the well-known and widely-distributed Phase Diagrams for Ceramists (PDFC). The software permits searches for diagrams by chemical system, author, or year of publication. All diagrams from volumes 1-8 in the PDFC series are included. After identifying figure numbers in a search, diagrams can be plotted on a screen. The graphics software permit diagram manipulation, such as magnification of selected regions, overlay of related diagrams, lever rule calculations, display of the cursor position in real units, and selection of the temperature scale. In addition, all bibliographic references from volumes 1-8 of the PDFC series are available.

This database comes in AT and PS2 versions.

A graphics screen from the Phase Diagrams for Ceramists Database.

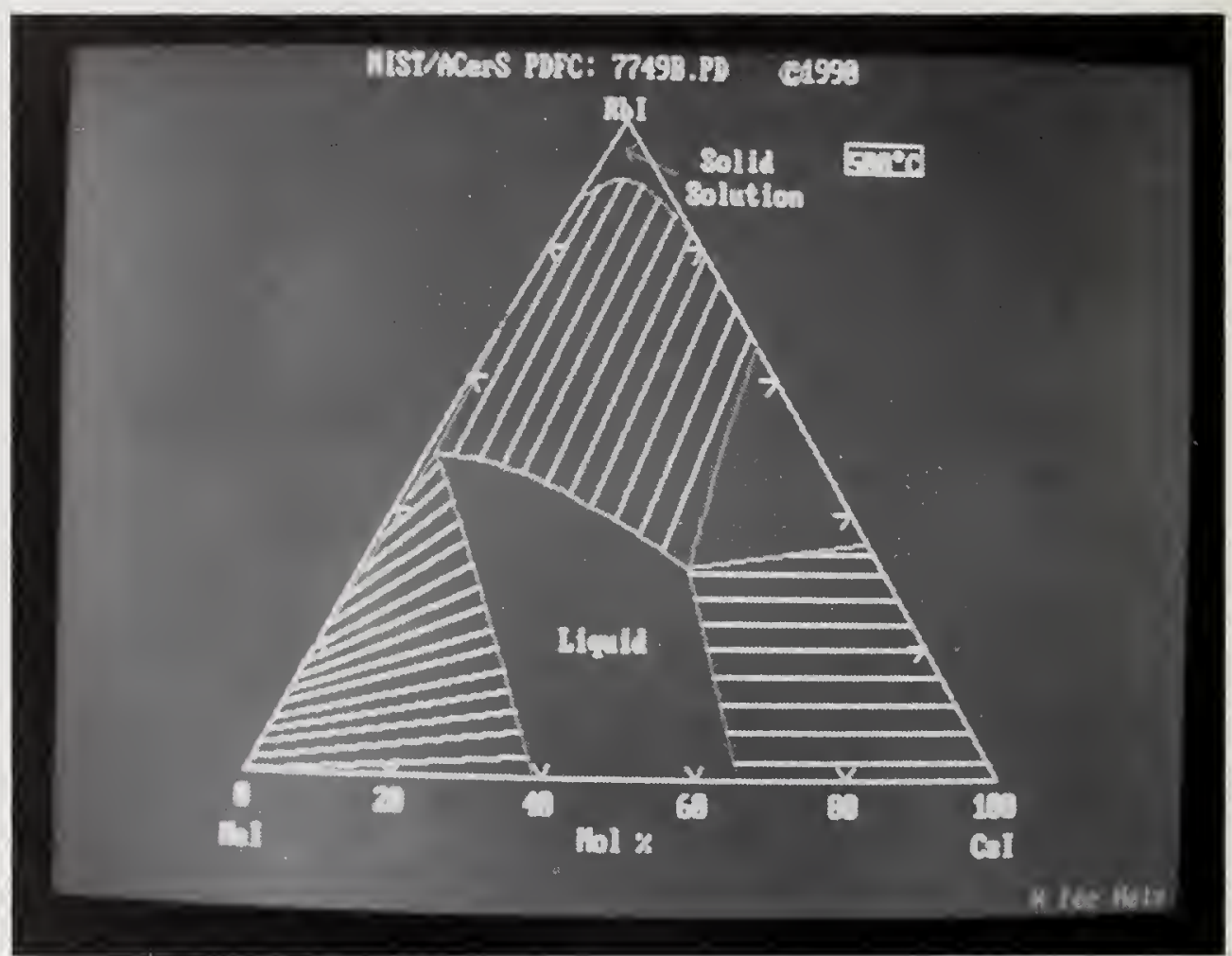




\title{
16. NACE-NIST Corrosion Performance Database
}

\author{
David Anderson \\ Corrosion Data Center \\ National Institute of Standards and Technology \\ Gaithersburg, MD 20899
}

(301) 975-6026

Three corrosion databases developed under the NACE-NIST Corrosion Data Program give users reference data for general guidance on the performance of engineering materials in corrosive environments. COR*SUR 1 includes data for 25 common metals for exposures in over 1,000 corrosive environments at various temperatures and concentrations. COR ${ }^{*}$ SUR 2 provides similar data for 36 nonmetallic materials (elastomers, polymers, composites, thermoplastics, etc.) in over 850 environments. Data can be retrieved from both programs by:

- tabular listing of materials exhibiting a specified range of corrosion rates in selected environments;

- graphic presentation of corrosion rate ranges for a given material in a matrix of environment, concentration, and temperature; and

- tabular listing of corrosion rate data for a specified material in a corrosive environment as a function of temperature and concentration.

The COR*DATA Corrosion database management system provides PC-based capability to corrosion scientists and engineers.

Programs are derived from Corrosion Data Survey publications produced by the National Association of Corrosion Engineers (NACE) and are available in diskette form for use on IBM or compatible personal computer systems and are available from NACE, P.O. Box 218340, Houston, TX 77218, phone (713) 492-0535.

\section{NIST Crystal Data (see page 8)}

NIST/Sandia/ICDD Electron Diffraction (see page 8)

NIST X-ray Photoelectron Spectroscopy (see page 9)

\section{Tribomaterials I Database}

\author{
Bill Ruff \\ Tribology Data Center \\ National Institute of Standards and Technology \\ Gaithersburg, MD 20899 \\ (301) 975-6010
}

This database contains property data for 261 materials commonly used in tribology applications. The data cover a wide range of properties including basic physical and mechanical, as well as tribology properties for both lubricated and unlubricated wear. This user-friendly PC database is available from ACTIS, 118 Highgate Road, Wilmington, DE 19808, phone (302) 998-8240. 


\section{MATERIALS PROPERTIES PUBLICATIONS}

Journal of Phase Equilibria (formerly the Bulletin of Alloy Phase Diagrams) - ASM International, Metals Park, $\mathrm{OH}$.

Beginning in February 1991, the Bulletin will be retitled and expanded to include original research on the generation and application of data to attain or prevent phase equilibria. It will present theoretical and experimental research on the determination of phase diagrams. It will also continue to provide critical phase diagram evaluations authored by international experts for scientifically and industrially important alloy systems and updates of systems previously published.

Available from ASM International, Metals Park, OH. (216) 338-5151

Binary Alloy Phase Diagrams, Second Edition, 3 vols. - ASM International, Metals Park, OH.

This is the most thorough alloy reference available. All systems published in the original set have been updated. This set contains 2,925 critical evaluations with key references, plus additional related citations. Available from ASM International, Metals Park, OH. (216) 338-5151, \$583.00

Phase Diagrams for Ceramists - American Ceramic Society, Columbus, OH.

This publication series has become the definitive source of ceramic phase diagrams in the scientific community. These nine volumes contain commentaries and binary, ternary, and higher-order phase diagrams of oxide, metals-oxide, and metal-oxygen systems, halide, and other ceramic systems.

Available from the American Ceramic Society, Columbus, OH. (614) 268-8645, \$125.00/vol.

Critical Compilation of Surface Structures Determined by Ion Scattering Methods - Philip R. Watson. Journal of Physical and Chemical Reference Data 19, 85 (1990).

This review critically compiles all surface structures derived by ion scattering techniques. These investigations cover all types of surfaces including clear and adsorbate-covered metal, semiconductor, and other nonmetallic substrates. The important experimental and theoretical aspects of such investigations have been extracted into easily understood tabular form supplemented by figures, ancillary tables, and complete references.

Available from the American Chemical Society, Reprint 376, \$6.00

Coupled Phase Diagram/Thermodynamic Analysis of the 24 Binary Systems, $\mathrm{A}_{2} \mathrm{CO}_{3}-\mathrm{AX}$ and $\mathrm{A}_{2} \mathrm{SO}_{4}$ - $\mathrm{AX}$ where $\mathrm{A}$ $=\mathrm{Li}, \mathrm{Na}, \mathrm{K}$ and $\mathrm{X}=\mathrm{Cl}, \mathrm{F}, \mathrm{NO}_{3}, \mathrm{OH}-$ Yves Dessureault, James Sangster, and Arthur D. Pelton. Journal of Physical and Chemical Reference Data 19, 1149 (1990).

A complete bibliographic search for all thermodynamic and phase diagram data on the 24 binary systems was carried out. A computer-assisted simultaneous evaluation of all data was performed in order to obtain optimized equations for the thermodynamic properties of the phases. These are considered to be the best evaluated phase diagrams which can be deduced from the data currently available.

Available from the American Chemical Society, Reprint 398, $\$ 6.00$ 


\section{MOLECULAR STRUCTURES AND SPECTROSCOPY}

Building upon the renowned NIST research on molecular spectroscopy and structure, the SRD Program has produced several important compilations of molecular data. Numerous comprehensive microwave spectra for astrophysically interesting molecules have been published and are widely used in radio astronomy. In addition, several comprehensive compilations of microwave spectral tables are now available.

A new database on vibrational and electronic lines has been prepared and will be updated yearly.

\section{SRD Molecular Structures and Spectroscopy Database}

NIST Vibrational and Electronic Energy Levels of Small Polyatomic Transient Molecules

\section{SRD Major Publications in Molecular Structures and Spectroscopy}

Microwave Spectral Tables III. Hydrocarbons

Electronic Energy Levels of Small Polyatomic Transient Molecules

Vibrational and Electronic Energy Levels of Polyatomic Transient Molecules 


\title{
26. NIST Vibrational and Electronic Energy Levels of Small Polyatomic Transient Molecules
}

\author{
Marilyn Jacox \\ National Institute of Standards and Technology \\ Gaithersburg, MD 20899 \\ (301) 975-2547
}

This database is designed to give rapid access to experimental data on vibrational and electronic energy levels of natural and transient molecules with from 3 to 6 atoms. Data on approximately 1,000 molecules are included. Searches can be made for a particular molecule, for a specific wavenumber, by electronic band origin, and by wavelength range for a transition. Searches can also be restricted to 1) molecules containing a specified chemical element; 2) either the ground or excited electronic states; 3 ) observations in the gas-phase or in a specified inert solid matrix; or 4) data obtained using a specific technique. Provision is made for the display of references to the original literature pertinent to each line of the compilation or of all references associated with the molecule of interest.

This database is available in XT, AT, and PS2 versions.

Dr. Marilyn Jacox developed VEEL - an important new database on vibrational and electronic lines.

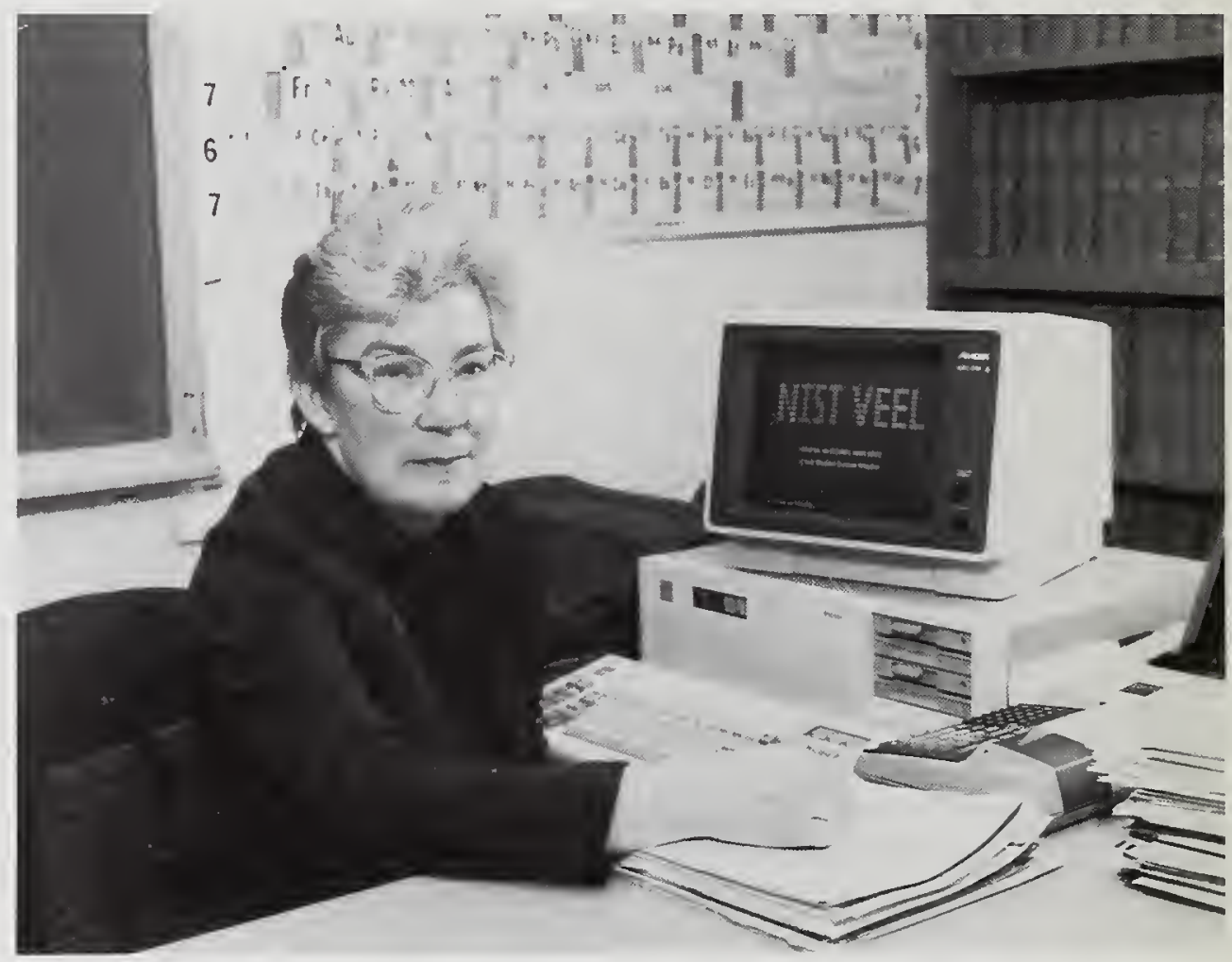




\section{MOLECULAR STRUCTURES AND SPECTROSCOPY PUBLICATIONS}

Microwave Spectral Tables III. Hydrocarbons, $\mathbf{C H}$ to $\mathrm{C}_{10} \mathrm{H}_{10}-\quad$ F. J. Lovas and R. D. Suenram. Journal of Physical and Chemical Reference Data 18, 1245 (1989).

All of the rotational spectral lines observed and reported in the open literature for 91 hydrocarbon molecules have been tabulated. The isotopic molecular species, assigned quantum numbers, observed frequency, estimated measurement uncertainty, and references are given for each transition reported. The derived molecular properties, such as rotational and centrifugal distortion constants, hyperfine structure constants, electric dipole moments, and rotational $\mathrm{g}$-factors are listed.

Available from the American Chemical Society, Reprint 369, $\$ 22.00$

Electronic Energy Levels of Small Polyatomic Transient Molecules - Marilyn E. Jacox. Journal of Physical and Chemical Reference Data 17, 269 (1988).

The experimentally determined electronic energy levels of approximately 500 neutral and ionic transient molecules possessing from 3 to 6 atoms are tabulated, together with the associated vibrational structure, the radiative lifetime, the principal rotational constants, and references to the present literature. Vibrational and rotational data for the ground state are also given. Observations in the gas-phase, in molecular beams, and in rare-gas and nitrogen matrices are included.

Available from the American Chemical Society, Reprint $342, \$ 20.00$

Vibrational and Electronic Energy Levels of Polyatomic Transient Molecules. Supplement 1 - Marilyn E. Jacox. Journal of Physical and Chemical Reference Data 19, Suppl. 1 (1990).

New information on the experimentally determined vibrational and electronic energy levels of approximately 470 neutral and ionic transient molecules possessing from 3 to 16 atoms has been evaluated and added to the previous established database for these species. Electronic spectral data are also given for a number of transient molecules which possess more than six atoms. Radiative lifetimes and the principal rotational constants are included. Observations in the gas-phase, in molecular beams, and in rare-gas and nitrogen matrices are evaluated.

Available from the American Chemical Society, Reprint 403 


\section{THERMODYNAMICS AND THERMOCHEMISTRY}

NIST has a long history as the source for reliable thermochemical data starting with the International Critical Tables from the 1920s. The tradition continues as new SRD databases on thermochemical properties of inorganic and small organic molecules gain acceptance.

The NIST Standard State Thermochemical Tables are recognized as the internationally authoritative source of standard state data for inorganics. The JANAF Thermochemical Tables contain the most complete compilations of evaluated temperature-dependent thermodynamic data for inorganic species. Specialized collections of data for water and aqueous electrolytes complement the standard collections. In addition, a number of detailed collections on specific families of organic and inorganic compounds are available.

NIST thermochemical databases are available both in convenient PC formats and as online systems.

\section{SRD Thermochemical Databases}

NIST Chemical Thermodynamics

NIST JANAF Thermochemical Tables

NIST Activity and Osmotic Coefficients of Aqueous Electrolyte Solutions

DIPPR Data Compilation of Pure Compound Properties

NIST Positive Ion Energetics

NIST Negative Ion Energetics

NIST Estimation of Thermodynamic Properties for Organic Compounds at $298.15 \mathrm{~K}$

NIST Molten Salts

NIST Structures and Properties

\section{SRD Major Publications in Thermochemistry}

NBS Tables of Chemical Thermodynamic Properties

JANAF Thermochemical Tables

NBS/NRC Steam Tables

Gas-Phase Ion and Neutral Thermochemistry 


\title{
THERMODYNAMIC AND THERMOCHEMICAL DATABASES
}

\section{NIST Chemical Thermodynamics Database \\ David Neumann \\ Chemical Thermodynamics Data Center \\ National Institute of Standards and Technology \\ Gaithersburg, MD 20899 \\ (301) $975-2525$}

This database contains recommended values for selected thermodynamic properties of more than 15,000 inorganic substances. These properties include the following:

Standard state properties at $298.15 \mathrm{~K}$ and $1 \mathrm{bar}$

- enthalpy of formation from the elements in their standard state

- Gibbs (free) energy of formation from the elements in their standard state

- entropy

- enthalpy $\mathrm{H}^{\circ}(298.15 \mathrm{~K})-\mathrm{H}^{\circ}(0 \mathrm{~K})$

- heat capacity at constant pressure

Properties at $0 \mathrm{~K}$

- enthalpy of formation

The database is not presently supplied with search software, but a PC version is currently in preparation. It is available in a magnetic tape format and online through STN and CIS.

\section{NIST JANAF Thermochemical Tables}

\author{
Malcolm W. Chase, Jr. \\ Standard Reference Data \\ National Institute of Standards and Technology \\ Gaithersburg, MD 20899 \\ (301) $975-2200$
}

The JANAF Thermochemical Tables provide a compilation of critically evaluated thermodynamic properties of approximately 1,800 substances over a wide range of temperatures. Recommended temperature-dependent values are provided for inorganic substances and for organic substances containing only one or two carbon atoms.

These tables cover the thermodynamic properties with single phase and multiphase tables for the crystal, liquid, and ideal gas states. The properties tabulated are heat capacity, entropy, Gibbs energy function, enthalpy, enthalpy of formation, Gibbs energy of formation, and the logarithm of the equilibrium constant for formation of each compound from the elements in their standard reference states. This database is consistent with the Third Edition of the JANAF Thermochemical Tables published as Supplement No. 1 to Volume 14 of the Journal of Physical and Chemical Reference Data.

This database is currently available as a magnetic tape with a PC product in preparation. It is currently online through STN. 


\title{
9. NIST Activity and Osmotic Coefficients of Aqueous Electrolyte Solutions
}

\section{R. N. Goldberg, J. L. Manley, and R. L. Nuttall Chemical Thermodynamics Division National Institute of Standards and Technology Gaithersburg, MD 20899}

(301) 975-2534

This database (called GAMPHI) provides values of activity and osmotic coefficients of binary aqueous electrolyte solutions at $298.15 \mathrm{~K}$ together with a collection of subroutines for utilizing this database. These thermodynamic properties are needed when performing equilibrium calculations on aqueous solutions.

Each binary electrolyte solution contains the name of the cation and anion in the binary salt; the literature reference from which the data were obtained; the minimum and maximum molality for which the data are valid; a designation of an internal database name to which the data set belongs; a designation as to whether or not the data are considered to be primary or nonprimary for a given salt in the entire database; an integer which indicates which equation or model is used to calculate the value of activity and osmotic coefficients; the number of parameters in the model and the parameters of the model.

This database is available in magnetic tape format.

\section{DIPPR Data Compilation of Pure Compound Properties}

\author{
T. E. Daubert and R. P. Danner \\ Penn State University \\ 133 Fenske Laboratory \\ University Park, PA 16802 \\ (814) 863-4638
}

The DIPPR database contains data on 39 properties for 1,117 chemical compounds of high industrial priority. Thermodynamic, physical, transport, and environmental property data are given. The database was prepared by Pennsylvania State University for the Design Institute for Physical Property Data, a cooperative project sponsored by 50 major chemical manufacturers and related companies under the auspices of the American Institute of Chemical Engineers.

For each chemical compound included, values are given for 26 single-valued property constants and for 13 properties as functions of temperature, calculated from correlation coefficients. The database also includes estimates of the accuracy of each property value and references to the sources of measured or predicted data which were used in selecting the recommended values. The database includes numeric values, as well as interactive software which allows access to specific properties of the compounds included, in any specified set of units.

This database is available in magnetic tape and diskette format. 


\title{
11A. DIPPR Data Compilation Access Program II
}

\section{Student DIPPR}

The student version of NIST Standard Reference Database 11 - DIPPR Data Compilation of Pure Compound Properties contains data for 100 compounds. For each compound, values are given for 26 single-valued property constants and for 13 properties as functions of temperature. The user can construct a list of compounds of interest from the available database, select any unit system, select the type of output device, and then plot or tabulate the properties of interest. An invaluable teaching tool, this database is available in diskette and magnetic tape format.

19A. NIST Positive Ion Energetics Database

\author{
Sharon G. Lias \\ Ion Energetics Data Center \\ National Institute of Standards and Technology \\ Gaithersburg, MD 20899 \\ (301) $975-2562$
}

This database provides rapid access to evaluated ionization potentials, enthalpies of formation of ions, enthalpies of formation of the corresponding neutral species, and all references to these data. The initial source of the database is the positive ion table in "Gas-Phase Ion and Neutral Thermochemistry," Journal of Physical and Chemical Reference Data, Volume 17, Supplement 1, 1988. Evaluated proton affinity values can also be retrieved. The database has a highly interactive interface that allows the user to retrieve data through three different search options: by empirical formula, by name, and by proton affinity.

19B. NIST Negative Ion Energetics Database

\author{
John E. Bartmess \\ University of Tennessee \\ Knoxville, TN 37996
}

(615) $974-6578$

Providing easy access to gas-phase electron affinities, acidities, negative-ion affinities to neutral species, negative-ion enthalpies of formation, and the literature references for the primary sources of the data, this database includes data on 2,000 negative ions. The species covered include all organic and inorganic atoms, molecules, and radicals for which pertinent data were found in the literature through the end of 1988 . Designed to accompany the NIST Positive Ion Energetics Database, this database also uses the Journal of Physical and Chemical Reference Data, Volume 17, Supplement 1, 1988 as an initial source.

Both databases come in PC diskette format. 
18. Estimation of the Thermodynamic Properties for Organic

Compounds at 298.15 K 1. Hydrocarbons

\author{
Eugene S. Domalski \\ Standard Reference Data \\ National Institute of Standards and Technology \\ Gaithersburg, MD 20899
}

(301) 975-2205

This database (also called THERM/EST) is an estimation algorithm which calculates thermodynamic properties at $298.15 \mathrm{~K}$ and contains a database with experimental and estimated values for 379 hydrocarbon compounds.

The thermodynamic properties calculated are:

- enthalpy of formation

- heat capacity

- entropy

- entropy of formation

- Gibbs energy of formation

- equilibrium constant for the formation reaction

The thermodynamic properties have been developed for the gas, liquid, and solid phases. The lists of the hydrocarbon compounds and their properties are divided into the following files:

- straight-chain aliphatic hydrocarbons

- branched aliphatic hydrocarbons/tertiary carbon branching

- branched aliphatic hydrocarbons/quaternary carbon branching
- straight-chain alkene hydrocarbons

- substituted alkene hydrocarbons

- alkyne hydrocarbons

- aromatic hydrocarbons

- alicyclic hydrocarbons

THERM/EST is available in an AT or PS2 version.

27. NIST Molten Salts Database

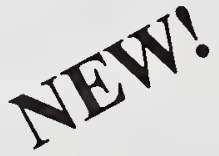

\section{George Janz}

Molten Salts Data Center

Rensselaer Polytechnic Institute

Department of Chemistry

Troy, NY 12181

(518) 276-6344

This database provides easy and rapid access to the properties of salt compounds in the molten state. This is the culmination of a long-term data evaluation project at RPI. The database allows calculation of the following properties of single salt systems:

- density

- surface tension
- viscosity

- electrical conductance

Data can be extracted by chemical formula, or the user can browse through the database to find the system of choice. All property value calculations display:

- the current salt system

- temperature measurement limits

- correlation equation
- accuracy estimates

- reliability statements

- results in a single temperature or range of temperatures in S/I units

Updates to this database include data for molten salts mixtures, both binary and ternary.

This database is available in AT and PS2 versions. 


\section{FUTURE DATABASE} NEW - SOATE! $B \mathbb{E}$
25. NIST Structures and Properties

Stephen E. Stein

Chemical Kinetics Division

National Institute of Standards and Technology

Gaithersburg, MD 20899

(301) $975-2505$

This database is a system for retrieving and estimating chemical properties or organic compounds on the basis of their structures. The present version will be devoted to the chemical thermodynamic properties of gas-phase molecules and free radicals. It has access to data for approximately 4,500 species taken from the NIST Chemical Kinetics Database and the NIST Positive Ion Energetics Database. Also included are chemical structures, which are displayed along with names to assist identification and used for property estimation and structure searching.

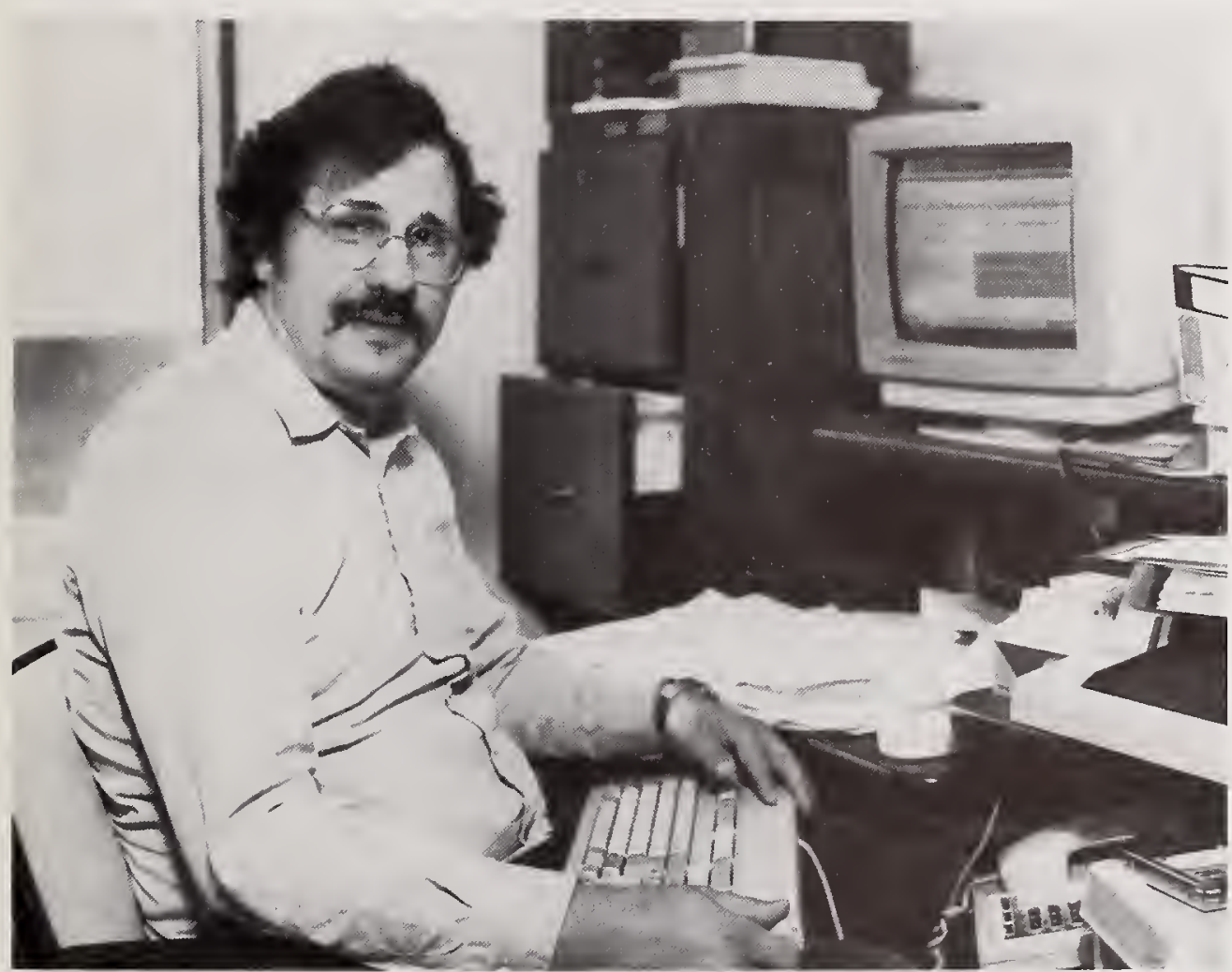

Dr. Stephen E. Stein is the developer of the upcoming NIST Structures and Properties Database.
The program contains a module for entering the structure of molecules of estimation and performs a complete implementation of Benson's group additivity method for chemical thermodynamic properties. In addition to the perception of "groups," the program perceives and corrects for specific rings, rotational symmetry, and other nongroup estimation terms.

In addition, molecular fragments may be drawn in "substructure searching." This search mode finds all molecules in the database containing a specified fragment. 


\section{THERMODYNAMIC AND THERMOCHEMICAL PUBLICATIONS}

The NBS Tables of Chemical Thermodynamic Properties. II. Selected Values for Inorganic and $C_{1}$ and $C_{2}$ Organic Substances in SI Units - Donald D. Wagman, William H. Evans, Vivian B. Parker, Richard H. Schumm, Iva Halow, Sylvia M. Bailey, Kenneth L. Churney, and Ralph L. Nuttall. Journal of Physical and Chemical Reference Data 11, Supplement 2 (1982).

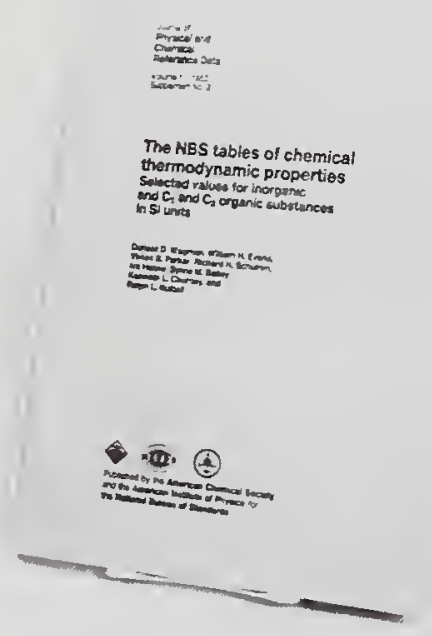

This publication provides the chemical thermodynamic properties of inorganic substances and organic substances usually containing only one or two carbon atoms. Where available, values are given for the enthalpy of formation, Gibbs energy of formation, entropy and heat capacity at $298.15 \mathrm{~K}$, the enthalpy difference between 298.15 and $0 \mathrm{~K}$, and the enthalpy of formation at $0 \mathrm{~K}$. All values are given in SI units and are for a standard state pressure of 100,000 pascal. Gaseous, liquid, and crystalline substances, solutions in water, and mixed aqueous and organic solutions are given values. This publication supersedes the National Bureau of Standards Technical Note 270 Series.

Available from the American Chemical Society

US and Canada $\$ 40.00$

Abroad $\$ \mathbf{4 8 . 0 0}$

JANAF Thermochemical Tables. Third Edition - M. W. Chase, Jr., C. A. Davies, J. R. Downey, Jr., D. J. Frurip, R. A. McDonald and A. N. Syverud. Journal of Physical and Chemical Reference Data 14, Supplement 1 (1985).

These updated volumes contain thermodynamic properties for more than 1,800 substances over a wide temperature range. All tables are in SI units and the notation has been made consistent with current international recommendations. There are single-phase and multi-phase tables in the crystal, liquid, and ideal gas states. The properties tabulated are heat capacity, entropy, Gibbs energy function, enthalpy of formation, Gibbs energy of formation, and the logarithm of the equilibrium constant for formation of each compound. Each tabulation is accompanied by a critical evaluation of the literature upon which the thermochemical table is based, and literature references are given.

Available from the American Chemical Society

US and Canada $\$ 130.00$

Abroad $\$ \$ 156.00$

CODATA Thermodynamic Tables. Selections for Some Compounds of Calcium and Related Mixtures: A Prototype Set of Tables - D. Garvin, V. B. Parker, and H. J. White, Jr. (editors). Hemisphere, NY (1987).

Prepared as the first of a series of cooperative, ongoing international projects, this volume presents recommended values for chemical thermodynamic properties of selected compounds of calcium and their mixtures. Forty-one tables of thermal functions (heat capacity, entropy, enthalpy, and Gibbs energy functions) are given for those compounds of magnesium, calcium, and potassium for which the properties have been evaluated in this work. Twenty-four tables of thermal functions are given for auxiliary substances.

Available from Hemisphere Press, NY. (800) 821-8312, $\$ 77.00$ 
Estimation of the Thermodynamic Properties of Hydrocarbons at 298.15 K - Eugene S. Domalski and Elizabeth D. Hearing. Journal of Physical and Chemical Reference Data 17, 1637 (1988).

This publication extends an estimation method for calculating the thermodynamic properties of organic compounds in the gas-phase to the liquid and solid phases for hydrocarbon compounds at $298.15 \mathrm{~K}$. A second order approach which includes nearest-neighbor interactions has been applied to the condensed phase. A total of 1,311 comparisons are made between experimentally determined values and those calculated using additive group values. Over 140 references indicate the development of estimation methods for calculating thermodynamic properties over the last five decades.

Available from the American Chemical Society, Reprint 351, $\$ 7.00$

Heat Capacities and Entropies of Organic Compounds in the Condensed Phase Volume II - Eugene S. Domalski and Elizabeth D. Hearing. Journal of Physical and Chemical Reference Data 19, 881 (1990).

This compilation provides data on approximately 1,300 organic compounds. A total of 565 articles have been examined, evaluated, and referenced. In addition to values for the heat capacity and entropy at $298.15 \mathrm{~K}$, phase transitions for solid/solid, solid/liquid, and in some instances, solid/gas and liquid/gas are tabulated as encountered from the articles examined and evaluated.

Available from the American Chemical Society, Reprint 393, \$15.00

Gas-Phase Ion and Neutral Thermochemistry - S. G. Lias, J. E. Bartmess, J. L. Holmes, R. D. Levin, J. F. Liebman, and W. G. Mallard. Journal of Physical and Chemical Reference Data 17, Supplement 1 (1988).

This volume includes evaluated ionization energies of 4,000 atoms and molecules and proton affinities of 1,000 compounds, as well as electron affinities and gas-phase acidities of approximately 3,000 species. The thermochemistry of the related neutral species is also provided.

Available from the American Chemical Society

US and Canada $\$ \mathbf{\$ 7 0 . 0 0}$

Abroad $\$ \mathbf{\$ 8 4 . 0 0}$

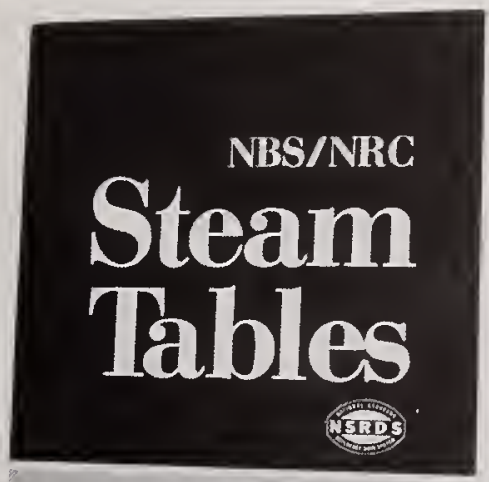

LESTER HAAR JOHN S. GALLAGHER GEORGE S. KELL
NBS/NRC Steam Tables - Lester Haar, John S. Gallagher, and George S. Kell. Hemisphere Press, NY (1984).

This landmark book presents a formulation for the properties of steam over a previously unavailable range of temperatures and pressures. Numerous thermophysical properties are tabulated, including specific volume, density, internal energy, enthalpy, and entropy. Approved by the National Institute of Standards and Technology and the International Association for the Properties of Steam and published in SI units, all physical states are calculated, including liquid, vapor, coexisting liquid/vapor, and metastables. Available from Hemisphere Press, NY. (800) 821-8312, \$23.95 
An equation has been fitted to values of the integrals in the Kirkwood dielectric-constant equation calculated from experimental values of the dielectric constant for temperatures from $238.15 \mathrm{~K}$ to $823.15 \mathrm{~K}$ and to pressures of approximately $500 \mathrm{MPa}$ for temperatures greater than $273 \mathrm{~K}$. The quality of representation of the experimental results has been compared to that of previous correlations of the dielectric constant. The new equation is applicable through wider regions of independent variables than the previous equations.

Available from the American Chemical Society, Reprint 383, $\$ \mathbf{7 . 0 0}$

Thermodynamic and Thermophysical Properties of Organic Nitrogen Compounds. Part I. Methanamine, Ethanamine, 1- and 2-Propanamine, Benzenamine, 2-, 3-, and 4-Methylbenzenamine - J. Chao, N. A. M. Gadalla, B. E. Gammon, K. N. Marsh, G. R. Somayajulu and R. C. Wilhoit. Journal of Physical and Chemical Reference Data 19 (1990).

The thermodynamic and thermophysical properties of eight primary amines, methanamine, ethanamine, 1- and 2-propanamine, benzenamine and 2-, 3-, and 4-methylbenzenamine have been evaluated. Recommended values are given for normal boiling, freezing and triple point temperature, critical constants, thermodynamic properties in the solid and liquid phases, vapor pressure, enthalpy of vaporization, density, second virial coefficients and enthalpy of combustion.

Available from American Chemical Society, Reprint 404 


\section{THERMOPHYSICAL PROPERTIES OF FLUIDS}

The complexity of providing reliable data on the thermophysical properties of fluid mixtures has been the focus of considerable attention of the SRD Program. Over the years, a set of combined theoretical and empirical predictive techniques have been developed that firmly rest on evaluated data. These techniques have been tested and incorporated into interactive computer programs that will provide a large variety of properties based upon the specified composition and the appropriate state variables.

Databases are now available for hydrocarbon mixtures, including natural gas, as well as a number of pure and mixed fluids of industrial importance. The database REFPROP has proven to be a valuable tool for refrigeration engineers, chemical and equipment manufacturers, and others who use chlorofluorocarbons.

\section{SRD Fluids Properties Databases}

NIST Thermophysical Properties of Hydrocarbon Mixtures

NIST Thermophysical Properties of Fluids

NIST Mixture Property Program

NIST Thermophysical Properties of Refrigerants and Refrigerant Mixtures

NIST Thermophysical Properties of Water

\section{SRD Major Publications in Fluids Properties}

Equilibrium and Transport Properties of Gas Mixtures at Low Density: Eleven Polyatomic Gases and Five Noble Gases

Thermal Conductivity of Nine Polyatomic Gases at Low Density

A Unified Equation of State for $\mathrm{H}_{2} \mathrm{O}$ 


\title{
THERMOPHYSICAL PROPERTIES OF FLUIDS DATABASES
}

\section{NIST Thermophysical Properties of Hydrocarbon Mixtures}

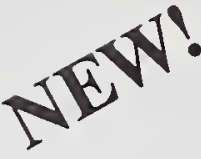

James F. Ely/Marcia Huber

Fluid Mixtures Data Center

National Institute of Standards and Technology

Boulder, CO 80303

(303) $497-3386$

This powerful database (also called SUPERTRAPP) is an interactive program for predicting thermodynamic properties of pure fluids and fluid mixtures of up to 20 components. The components are selected from a database of 116 components, mostly hydrocarbons. SUPERTRAPP performs phase equilibria calculations and gives the thermodynamic properties of all phases and the feed. These results include:

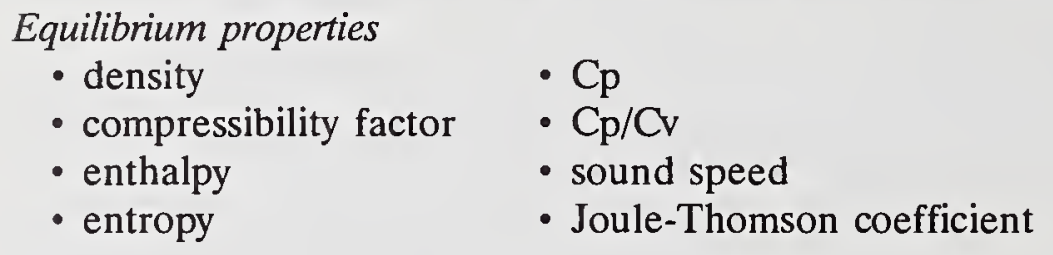

Transport properties
- viscosity
- thermal conductivity

SUPERTRAPP features commands that allow you to:

- perform bubble point pressure calculations

- perform dew point pressure calculations

- perform isothermal flash calculations

- obtain properties of pure components along the saturation boundary

- produce tables of properties along isobars or isotherms

- change units

- learn (and remember) a new component not in the current database

- enter data from the keyboard or from data files

- save results in a file

SUPERTRAPP comes in XT or PS2 versions.

12. NIST Thermophysical Properties of Fluids

\author{
James F. Ely \\ National Institute of Standards and Technology \\ Fluid Mixtures Data Center \\ Boulder, CO 80303 \\ (303) 497-3386
}

This interactive database (called MIPROPS) computes thermophysical properties of 12 important industrial pure fluids: helium, argon, parahydrogen, oxygen, nitrogen, nitrogen trifluoride, ethylene, methane, ethane, propane, isobutane, and normal butane. The database provides prompting for selection of several options including choice of fluid, choice of units, and choice of single-phase or liquid-vapor phase calculations.

Properties are computed for the single-phase region from input of two of the following variables: temperature, pressure, and density. Values on the liquid-vapor boundary are computed for either a given temperature or a given pressure. The database returns values for pressure, temperature, density, internal energy, enthalpy, entropy, specific heats at constant volume, pressure, and sound velocity. Viscosity, thermal conductivity, and dielectric constants are given for five of the fluids.

This database is available in PC diskette and magnetic tape format. 


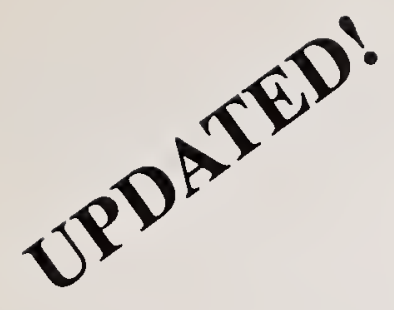

\section{NIST Thermodynamic Properties of Refrigerants and Refrigerant Mixtures}

John S. Gallagher

Thermophysics Division

National Institute of Standards and Technology

Gaithersburg, MD 20899

(301) $975-2455$

Version 2.0 of REFPROP calculates the thermodynamic properties of pure refrigerants and binary mixtures. The database enables the user to screen several environmentally acceptable ethane-based refrigerants and refrigerant mixtures as possible replacements for those currently used. The tables provided can be used to determine the efficiency and capability of a wide range of equipment that will be used with alternative refrigerants.

The user selects the refrigerant or refrigerant mixture of interest. REFPROP provides tables of saturation properties at desired temperatures or pressures, as well as tables of properties using any of the following as independent variables: pressure, temperature, entropy, or enthalpy. Dependent variables include those mentioned plus constant-pressure and constant-volume heat capacities and speed of sound. Version 2.0 has algorithms that calculate five-component mixtures and includes ten mixing parameters for new mixtures.

This database comes in XT and PS2 versions.

Dr. John S. Gallagher, programmer of the REFPROP database.

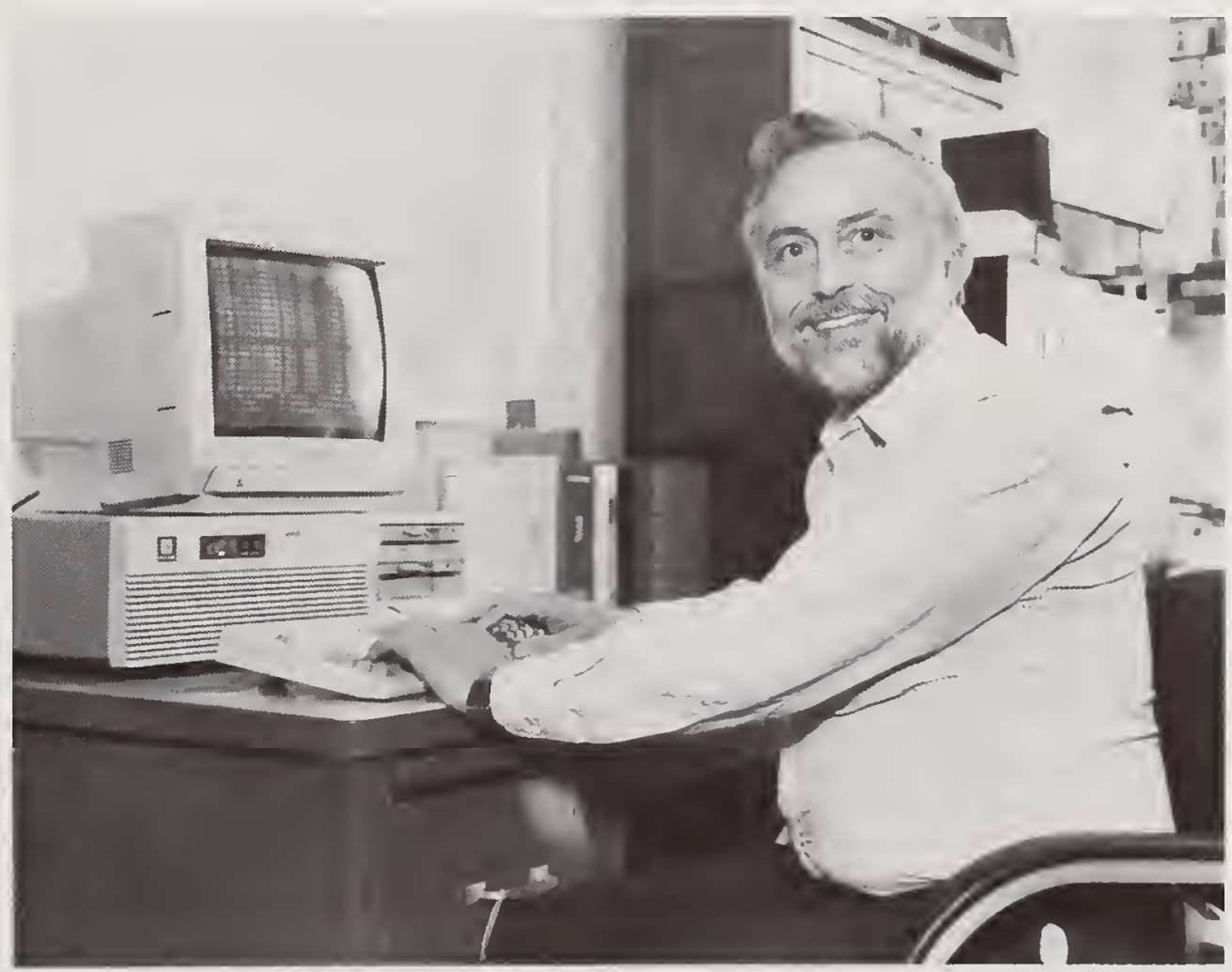




\title{
14. NIST Mixture Property Database
}

\author{
James F. Ely \\ Fluid Mixtures Data Center \\ National Institute of Standards and Technology \\ Boulder, CO 80303 \\ (303) 497-3386
}

The NIST Mixture Property Database (also called DDMIX) is a database which calculates various thermodynamic and transport properties of mixtures of fluids selected from any of 17 possible pure components. The emphasis of the database is on density prediction (especially for $\mathrm{CO}_{2}$-rich mixtures), but it will provide accurate results for other properties and mixtures.

All phase equilibrium calculations are performed with the Peng-Robinson equation of state, and co-existing phase properties are calculated with the NIST extended corresponding states model (DDMIX). Mixtures formed from any of 17 pure components (including hydrocarbons, nitrogen, oxygen, argon, carbon monoxide, carbon dioxide, and hydrogen sulfide) are handled by the database.

DDMIX provides the following outputs for any specified mixture:

- bubble point pressure

- dew point pressure

- saturation properties

- tables of density, enthalpy, entropy, and heat capacity as functions of T or $\mathrm{P}$

- isothermal flash calculation yielding density, enthalpy, entropy, heat capacity, viscosity, and thermal conductivity of feed and vapor

This database is available in XT diskette format.

\section{NIST Thermophysical Properties of Water}

\author{
John S. Gallagher \\ Thermophysics Division \\ National Institute of Standards and Technology \\ Gaithersburg, MD 20899 \\ (301) $975-2455$
}

This database consists of an interactive program which calculates the thermodynamic properties of fluid $\mathrm{H}_{2} \mathrm{O}$ (liquid and vapor) using the formulation as approved by the International Association for the Properties of Steam (IAPS) at its Tenth International Conference in 1984.

The interactive FORTRAN 77 program consists of three parts. The first part contains a package of subroutines to calculate the thermodynamic and transport properties of fluid $\mathrm{H}_{2} \mathrm{O}$. The other parts are main programs which call these routines to generate properties of $\mathrm{H}_{2} \mathrm{O}$ interactively.

The main program allows the calculation and display of all properties at a single pair of independent variables:

$\begin{array}{ll}\text { pressure - temperature } & \text { enthalpy - temperature } \\ \text { density - temperature } & \text { enthalpy - pressure }\end{array}$

entropy - temperature

The second main program allows the generation of tables of properties along isotherms, isobars, or isochores. To keep the tabular form compact, the user may choose which properties are to be displayed.

The range approved by IAPS for this formulation includes temperatures from 0 to $1000{ }^{\circ} \mathrm{C}$ and pressures up to $1500 \mathrm{MPa}$. The range over which usable results will be obtained extends to $2500 \mathrm{~K}$ and to $3000 \mathrm{MPa}$. This database is available in both magnetic tape and PC diskette versions.

The printed version of this database, which includes a description of the data selection and evaluation procedures, is found in NBS/NRC Steam Tables - L. Haar, J. S. Gallagher, and G. S. Kell, Hemisphere Press, Washington, DC (1984). 


\section{THERMOPHYSICAL PROPERTIES OF FLUIDS PUBLICATIONS}

Equilibrium and Transport Properties of Gas Mixtures at Low Density: Eleven Polyatomic Gases and Five Noble Gases - J. Bzowski, J. Kestin, E. A. Mason, and F. J. Uribe. Journal of Physical and Chemical Reference Data 19, 1179 (1990).

This paper uses results from statistical-mechanical theory, applied through a combination of an extended principle of corresponding states with some knowledge of intermolecular potentials, to the calculation of the transport and equilibrium properties of gas mixtures at low density. The properties calculated are second virial coefficient, viscosity, diffusion, and thermal diffusion.

Available from the American Chemical Society, Reprint 399, $\$ 8.00$

Thermal Conductivity of Nine Polyatomic Gases at Low Density - F. J. Uribe, E. A. Mason, and J. Kestin. Journal of Physical and Chemical Reference Data 19, 1123 (1990).

This paper presents a complete set of easily-programmable computer algorithms, and a set of numerical tables for the thermal conductivities of nine gases: $\mathrm{N}_{2}, \mathrm{O}_{2}, \mathrm{NO}, \mathrm{CO}, \mathrm{CO}_{2}, \mathrm{~N}_{2} \mathrm{O}, \mathrm{CH}_{4}, \mathrm{CF}_{4}$, and $\mathrm{SF}_{6}$. The accuracy achieved is specified and the correlation can be used in a predictive mode.

Available from the American Chemical Society, Reprint 396, $\$ 5.00$

A Unified Equation of State for $\mathrm{H}_{2} \mathrm{O}$ - Philip G. Hill. Journal of Physical and Chemical Reference Data 19, 1231 (1990).

A new unified equation of state for $\mathrm{H}_{2} \mathrm{O}$ is continuous over all single phase states of $\mathrm{H}_{2} \mathrm{O}$ from triple point pressure and temperature from $1000 \mathrm{MPa}$ (or the melting line) to $1000{ }^{\circ} \mathrm{C}$ and provides accurate representation of existing thermodynamic data in that range. In addition, it provides a smooth transition from singular critical region functions to the non-singular far-field functions. This is demonstrated by the variations of isochoric specific heat, isothermal compressibility, speed of sound, specific heat ratio, and coexistence line properties in the critical region.

Available from the American Chemical Society, Reprint 400, $\$ 7.00$ 


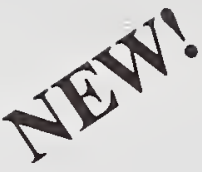

\author{
1. NIST Binary Images of Printed Digits, Alphas, \\ and Text \\ Charles Wilson \\ National Institute of Standards and Technology \\ Gaithersburg, MD 20899 \\ (301) $975-2080$
}

The NIST handprinted character database consists of 2,100 pages of bilevel, black and white image data of hand printed numerals and text with a total character count of over $1,000,000$ characters. This database totals approximately 3 gigabytes of image data with 273,000 numerals and 707,700 alphabetic characters. With the sample taken from the Bureau of Census field staff and also geographically sampled, the database has the following features:

- over $1,000,000$ character images

- 300 pixel/inch resolution

- images of full pages of data

- images of numbers with $2,3,4$, 5 , and 6 digits

- images of full alphabets

- images of unconstrained text

Suitable for both character recognition system research, development, and evaluation, the data set can be used for:

- field isolation: locating the text on the page

- character segmentation: separating the text into characters

- character recognition: identifying specific characters

The database is also a valuable tool for measurement of system performance and system comparison.

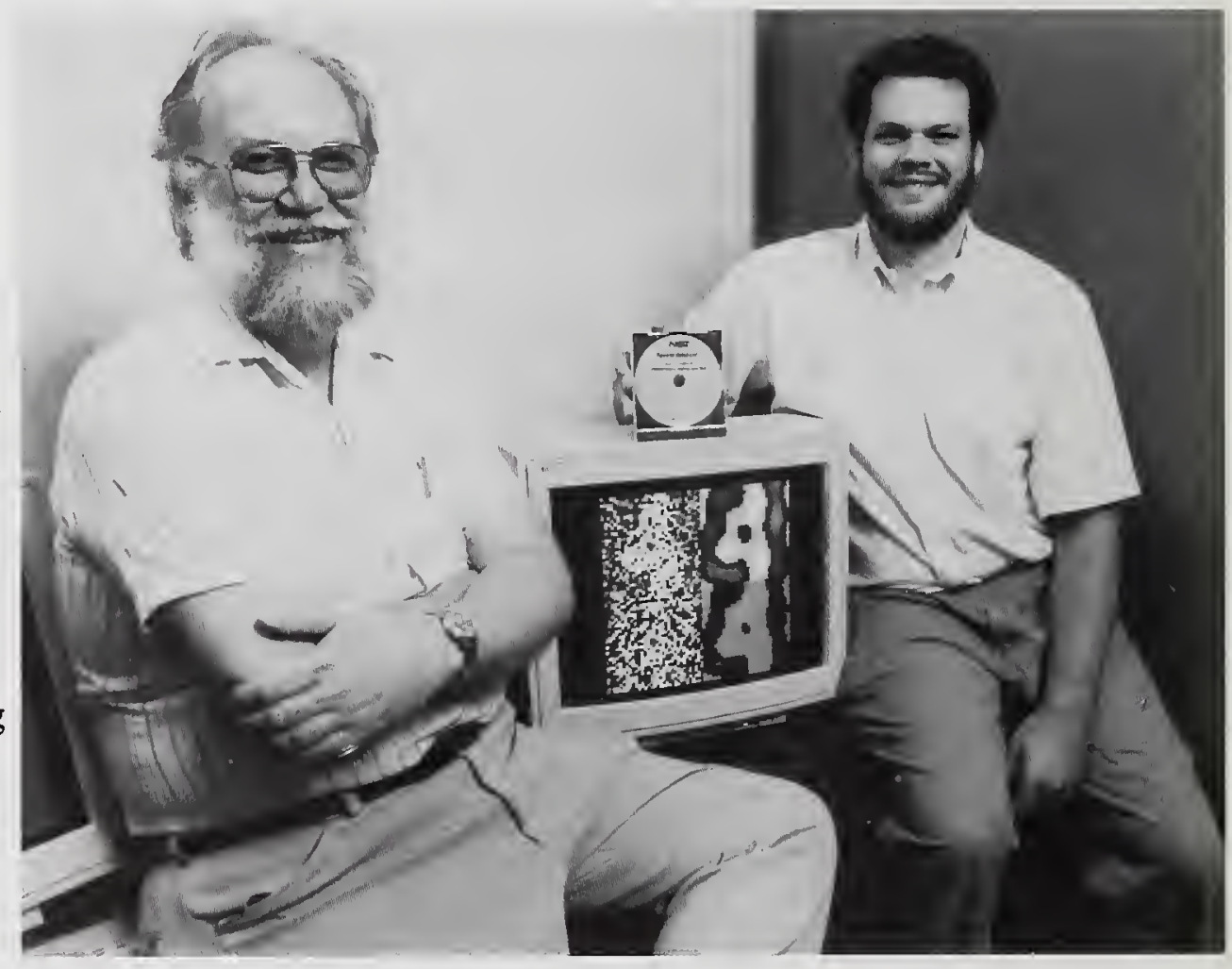

Charles Wilson (l) and Michael Garris display the new database on printed digits, alphas, and text.

The system requirements are a CD-ROM drive with software to read ISO 9660 format. 


\section{ORDER FORM}

The following prices on databases represent one location individual use. For distributor agreements, online agreements, and more than one location pricing, please contact Standard Reference Data.

I would like more information on the databases checked.

I am ordering the databases checked. I am enclosing a check or purchase order payable to the National Institute of Standards and Technology.

\begin{tabular}{|c|c|c|c|}
\hline$\square$ & 1. & NIST/EPA/MSDC Mass Spectral & $\$ 3,300.00$ \\
\hline$\square$ & 1A. & NIST/EPA/MSDC Mass Spectral: PC Version & $1,050.00$ \\
\hline$\square$ & $1 B$. & NIST Mass Spectral Database of Common Compounds & 350.00 \\
\hline$\square$ & 2. & NIST Chemical Thermodynamics & $1,000.00$ \\
\hline$\square$ & 3. & NIST Crystal Data Identification ${ }^{1}$ & $2,000.00$ \\
\hline$\square$ & 4. & NIST Thermophysical Properties of Hydrocarbon Mixtures & 490.00 \\
\hline$\square$ & 7. & NIST Electron and Positron Stopping Powers and Ranges & 350.00 \\
\hline$\square$ & 8. & NIST X-ray and Gamma-ray Attenuation Coefficients and Cross Sections & 400.00 \\
\hline$\square$ & 9. & NIST Activity and Osmotic Coefficients and Cross Sections & 200.00 \\
\hline$\square$ & 10. & NIST Thermophysical Properties of Water & 300.00 \\
\hline$\square$ & 11. & DIPPR Data Compilation of Pure Compound Properties Version 5 & $3,400.00$ \\
\hline$\square$ & 11A. & Student DIPPR & 75.00 \\
\hline$\square$ & 12. & NIST Thermophysical Properties of Fluids & 400.00 \\
\hline$\square$ & 13. & NIST JANAF Thermochemical Tables & $1,200.00$ \\
\hline$\square$ & 14. & NIST Mixture Property Program & 400.00 \\
\hline$\square$ & 15. & NIST/Sandia/ICDD Electron Diffraction ${ }^{1}$ & $3,000.00$ \\
\hline$\square$ & 16. & COR*SUR $1^{2}$ & 270.00 \\
\hline & & COR*SUR2 $2^{2}$ & 240.00 \\
\hline & & COR $^{*}$ DATA PLUS ${ }^{2}$ & 595.00 \\
\hline$\square$ & 17. & NIST Chemical Kinetics & 300.00 \\
\hline$\square$ & 18. & NIST Estimation of the Thermodynamic Properties for Organic Compounds at $298.15 \mathrm{~K}$ & 215.00 \\
\hline & A\&B. & NIST Positive and Negative Ion Energetics & 130.00 \\
\hline$\square$ & 20. & NIST X-ray Photoelectron Spectroscopy & 495.00 \\
\hline$\square$ & 21. & NIST/CARB Biological Crystallization Macromolecule & 300.00 \\
\hline$\square$ & 22. & Tribomaterials $\mathrm{I}^{3}$ & 350.00 \\
\hline$\square$ & 23. & NIST Thermodynamic Properties of Refrigerants and Refrigerant Mixtures Version 2.0 & 340.00 \\
\hline$\square$ & 24. & NIST Atomic Transition Probabilities & 215.00 \\
\hline$\square$ & 26. & NIST Vibrational and Electronic Energy Levels of Small Polyatomic Transient Molecules & 390.00 \\
\hline$\square$ & 27. & NIST Molten Salts & 190.00 \\
\hline$\square$ & 30. & NIST Structural Ceramics & 495.00 \\
\hline$\square$ & 31. & NIST Phase Diagrams for Ceramists & 550.00 \\
\hline
\end{tabular}

\section{NIST Special Database}

1. NIST Binary Images of Printed Digits, Alphas, and Text

${ }^{1}$ Available from the JCPDS-International Centre for Diffraction Data, 1601 Park Lane, Swarthmore, PA 19081. Phone: (215) 328-9400. ${ }^{2}$ Available from NACE, P.O. Box 218340, Houston, TX 77218. Phone: (713) 492-0535.

${ }^{3}$ Available from ACTIS Inc., 1118 Highgate Rd., Wilmington, DE 19808. Phone: (302) 998-8240.

Send orders to:

STANDARD REFERENCE DATA

NATIONAL INSTITUTE OF STANDARDS

AND TECHNOLOGY

221/A320

GAITHERSBURG, MD 20899

(301) 975-2208

(301) 926-0416 (FAX)
For Journal of Physical and Chemical Refcrence Data, reprints and monographs, contact:
AMERICAN CHEMICAL SOCIETY
1155 16th ST., N.W.
WASHINGTON, D.C. 20036
(202) 872-4405 

NIST-114A
(REV. 3-90)
U.S. DEPARTMENT OF COMMERCE NATIONAL INSTITUTE OF STANDARDS AND TECHNOLOGY BIBLIOGRAPHIC DATA SHEET

1. PUBLICATION OR REPORT NUMBER

NIST/SP-782, 1991 Edition

2. PERFORMING ORGANIZATION REPORT MUMBER

3. PUEUCATION DATE

February 1991

4. TITLE AND SUBTITLE

NIST Standard Reference Data Products 1991 Catalog

5. AUTHOR(S)

Malcolm W. Chase, Jr. and Joan C. Sauerwein (editors)

6. PERFORMING ORGANIZATION (IF JOINT OR OTHER THAN NIST, SEE INSTRUCTIONS)

U.S. DEPARTMENT OF COMMERCE

NATIONAL INSTITUTE OF STANDARDS AND TECHNOLOGY

GAITHERSBURG, MD 20899

7. CONTRACT/GRANT NUMBER

8. TYPE OF REPORT AND PEAIOD COVERED

Final

9. SPONSOAING ORGANIZATION NAME AND COMPLETE ADDRESS (STREET, CITY, STATE, ZIP)

Same as item \#6

10. SUPPLEMENTARY NOTES

Supersedes NIST Special Publication 782

11. ABSTRACT (A 200-WORD OR LESS FACTUAL SUMMARY OF MOST SIGNIFICANT INFORMATION. IF DOCUMENT INCLUDES A SIGNIFICANT BIBLOGRAPHY OR UTERATURE SURVEY, MENTION IT HERE.)

The National Institute of Standards and Technology's Standard Reference Data Program provides reliable, well-documented data to scientists and engineers for use in tecinical problem-solving, research, and development. This catalog lists classic jata compilations in hard-copy form and current databases in the Standara Reference Database Series. This edition of the catalog updates many new databases. The data compilations have been subdivided into seven categories. Prices and ordering information are located at the back of the document.

12. KEY WORDS (6 TO 12 ENTRIES; ALPHABETICAL ORDER; CAPITALZE ONLY PROPER NAMES; AND SEPARATE KEY WORDS BY SEMICOLONS) atomic physics; chemistry; compilations; database; materials; numeric data

13. AVAILABIUTY

$\mathrm{X}$ UNUMITED

FOR OFFICIAL DISTRIBUTION. DO NOT RELEASE TO NATIONAL TECHNICAL INFORMATION SERVICE (NTIS).

ORDER FROM SUPERINTENDENT OF DOCUMENTS, U.S. GOVERMMENT PRINTING OFFICE, WASHINGTON, DC 20402.

ORDER FROM MATIONAL TECHNICAL INFORMATION SERVICE (NTIS), SPRINOFIELD, VA 22161.
14. NUMBER OF PAINTED PAGES

52

15. PAICE 


\section{NTSTT Technical Publications}

\section{Periodical}

Journal of Research of the National Institute of Standards and Technology-Reports NIST research and development in those disciplines of the physical and engineering sciences in which the Institute is active. These include physics, chemistry, engineering, mathematics, and computer sciences. Papers cover a broad range of subjects, with major emphasis on measurement methodology and the basic technology underlying standardization. Also included from time to time are survey articles on topics closely related to the Institute's technical and scientific programs. Issued six times a year.

\section{Nonperiodicals}

Monographs-Major contributions to the technical literature on various subjects related to the Institute's scientific and technical activities.

Handbooks-Recommended codes of engineering and industrial practice (including safety codes) developed in cooperation with interested industries, professional organizations, and regulatory bodies.

Special Publications-Include proceedings of conferences sponsored by NIST, NIST annual reports, and other special publications appropriate to this grouping such as wall charts, pocket cards, and bibliographies.

Applied Mathematics Series-Mathematical tables, manuals, and studies of special interest to physicists, engineers, chemists, biologists, mathematicians, computer programmers, and others engaged in scientific and technical work.

National Standard Reference Data Series-Provides quantitative data on the physical and chemical properties of materials, compiled from the world's literature and critically evaluated. Developed under a worldwide program coordinated by NIST under the authority of the National Standard Data Act (Public Law 90-396). NOTE: The Journal of Physical and Chemical Reference Data (JPCRD) is published quarterly for NIST by the American Chemical Society (ACS) and the American Institute of Physics (AIP). Subscriptions, reprints, and supplements are available from ACS, 1155 Sixteenth St., NW., Washington, DC 20056.

Building Science Series-Disseminates technical information developed at the Institute on building materials, components, systems, and whole structures. The series presents research results, test methods, and performance criteria related to the structural and environmental functions and the durability and safety characteristics of building elements and systems.

Technical Notes-Studies or reports which are complete in themselves but restrictive in their treatment of a subject. Analogous to monographs but not so comprehensive in scope or definitive in treatment of the subject area. Often serve as a vehicle for final reports of work performed at NIST under the sponsorship of other government agencies.

Voluntary Product Standards-Developed under procedures published by the Department of Commerce in Part 10, Title 15, of the Code of Federal Regulations. The standards establish nationally recognized requirements for products, and provide all concerned interests with a basis for common understanding of the characteristics of the products. NIST administers this program as a supplement to the activities of the private sector standardizing organizations.

Consumer Information Series-Practical information, based on NIST research and experience, covering areas of interest to the consumer. Easily understandable language and illustrations provide useful background knowledge for shopping in today's technological marketplace.

Order the above NIST publications from: Superintendent of Documents, Government Printing Office, Washington, DC 20402.

Order the following NIST publications-FIPS and NISTIRs-from the National Technical Information Service, Springfield, VA 22161.

Federal Information Processing Standards Publications (FIPS PUB)-Publications in this series collectively constitute the Federal Information Processing Standards Register. The Register serves as the official source of information in the Federal Government regarding standards issued by NIST pursuant to the Federal Property and Administrative Services Act of 1949 as amended, Public Law 89-306 (79 Stat. 1127), and as implemented by Executive Order 11717 (38 FR 12315, dated May 11, 1973) and Part 6 of Title 15 CFR (Code of Federal Regulations).

NIST Interagency Reports (NISTIR) - A special series of interim or final reports on work performed by NIST for outside sponsors (both government and non-government). In general, initial distribution is handled by the sponsor; public distribution is by the National Technical Information Service, Springfield, VA 22161, in paper copy or microfiche form. 
